\title{
1. Innovation through boundaries vision and dynamic capabilities: the strategic management perspective
}

\author{
Mitsuru Kodama
}

\section{BACKGROUND AND OBJECTIVES OF THIS BOOK}

It goes without saying that raising creativity across generations to contribute to wide-ranging social activities is important, not only for corporate organizations, but also in wider social organizations and individual people. In recent years in the business world, there has been heightened interest in new product and service developments brought about through "knowledge convergence" (or knowledge creation/knowledge integration) (Nonaka and Takeuchi, 1995; Kodama, 2011) that entails fusing dissimilar technologies and services as new product developments that differentiate from other companies or as novel business developments in different fields. This is because there are now many cases of never-before-seen and uniquely creative new products and services achieved through the merging of knowledge from one field with those of another (Kodama, 2007b).

For example, the necessity to develop business strategies to respond to convergence, such as that of differing technologies and services, or of product and service developments and new business model formation across dissimilar industries, is becoming more and more pronounced. There is also a strengthening of training and employment of personnel who think creatively at the corporate side. Against this backdrop, this book focuses on the thinking and actions of organizations and individuals for creative thinking and innovation, and is aimed at research on a theoretical framework for creating knowledge and developing creativity.

In business studies and psychology to date, the importance of "intrinsic motivation" has been identified as a factor in raising creativity (see Figure 1.1) (e.g., Elsbach and Hargadon, 2006). Intrinsic motivation raises personal interests, curiosity and the desire to learn as well as knowledge flexibility and sustainability, and further raises creativity (Ryan and Deci, 2000; Shalley et al., 2004). However, regarding thinking on creativity, intrinsic motivation has been reported in past empirical research as not necessarily raising creativity, depending on whether the focus is on novelty or utility (e.g., Amabile, 1996; George and Zhou, 2007). Conventional motivational information processing theory has the focus of intrinsic motivation on novelty, and not necessarily on utility.

Amabile (1996) asserts that psychological effects come into play in the shift from novelty born of ideas that have come about from intrinsic motivation to the subsequent stage - i.e., utility (usefulness). In this perspective, it is important that "creativity" includes both novelty 
and utility, and it should achieve new creations or events that impact broadly on society (in other words innovation). Centered on Amabile (e.g., 1988, 1995), there is an accumulation of academic research on creativity in the fields of psychology and business studies. However, much of this research presents only spot relationships regarding causality and relationships between factors, and does not fully clarify why such results occur, or the micro processes fundamental to the acquisition of creativity.

On the other hand, traditional organizational learning theory discusses development of individual and organizational capabilities and the related processes of practice (e.g., Cyert and March, 1963). However, learning is not the same as creativity. Creativity entails producing something that has not existed in the past, but does not mean something is created from nothing. Creativity is finding new combinations of existing knowledge and objects (e.g., Zhou and Shalley, 2007). Put in terms of cognitive science, as opposed to learning, which is the process of enriching networks by incorporating new information into existing knowledge networks, creativity is the process of forming new links between existing and dissimilar networks (e.g., Fauconnier and Turner, 1998). Although both learning and creativity enrich knowledge networks, the processes to arrive at that state are not the same. In other words, learning involves forming linkages with information from outside, while the spontaneous occurrence of information is creativity. Thus, learning comes from externalities such as teachers or teaching materials, while creativity requires spontaneously searching and newly combining knowledge for self-realization from within - opportunities come from the outside, but the discovery of solutions is a process that is spontaneous and generative.

There is hardly any existing creativity-based research on strategy in the field of strategic management. Currently, "sensing" (Teece, 2007), a sub-capability of the dynamic capabilities framework in focus in the field of strategy, is a crucial element consisting of capabilities required for scrutiny, creation, learning and interpretation, and investment of it in research and related activities is crucial. In particular, the capability to sense the emergence of threats or opportunities (sensing) is a fundamental factor of corporate responses to unstable markets, uncertain technologies and unpredictable competitors. Sensing requires constant alertness through scrutiny, investigation and searching by surveying latent customer needs, exploratory investments into related technologies and timely intelligence gathered from various parts of ecosystems.

Nevertheless, leading practitioners are even more aware of the fundamental importance of intuition (an aspect of creativity) in the sensing process, which results in their ability to react quickly to stimulation and recognize opportunities (Hodgkinson and Healey, 2011). While sensing is rooted in perception and attention capability, in contrast, perceptions and interpretations of unexpected new information are steered by previous knowledge (Helfat and Martin, 2015). However, not much has been clarified on the relationship between creativity and this kind of sensing. Also, although literature on organizational management presents a range of sensing processes, including March's (1981) distinction of exploration and exploitation through to the concept of the ambidextrous organization that balances creativity with efficiency, etc., not much detail has been clarified about the processes of bringing about creativity.

In addition, Nonaka and Takeuchi's (1995) knowledge creation theory focuses on subjective and corporeal tacit knowledge and Aristotle's "phronesis" as the sources of internal commitment. The fundamental differences of these are that the roots of learning theory lie in the behavioral theory of stimulation-reaction, whereas the roots of Nonaka's knowledge 
creation theory lie in the philosophies of ontology and epistemology. Organizational learning theory is how-to oriented, but is not based on any theoretical construction that searches for truth, goodness and beauty, such as human reasons for existence or self-realization as sources of knowledge. In comparing these two main theories (organizational learning and knowledge creation theories), organizational learning theory also advocates the concept of "double loop learning" in terms of supplementation of passive learning, although that process has so far not been clarified (e.g., Argyris, 2004).

On the other hand, Nonaka et al. propose knowledge creation processes through a triad structure of tacit knowledge, explicit knowledge and phronesis (Nonaka et al., 2014; Kodama, 2018c), but have not presented great detail on creative practical processes. Also, in traditional academic research on innovation management, the main focus is on industry policy and research and development (R\&D) organizational management, but there is little perspective focusing on the micro creative processes of people and organizations.

While there is much research accumulated in the fields of business studies and psychology as described above, there has not been much clarification on the particular factors and practical processes that bring about creativity (novelty and utility) (see Figure 1.1). Against this academic backdrop, and with the aim of contributing to existing research, this book presents the new concept of "boundaries knowledge (knowing)" and "boundaries vision" in the thinking of individuals, which are both frameworks and processes to accelerate knowledge creation as dynamic creativity at the micro level.

This book will focus on the new concept of "knowledge differences" that arise between people, organizations, and various different objects and events, and names the new knowledge that comes about through the awareness, perception and discovery by people of such differences as "boundaries knowledge" (or "boundaries knowing"). In the past, this boundaries knowledge (knowing) has hardly been discussed (taken up) in the field of knowledge management or business management or in other academic fields (such as the social sciences or humanities). This book identifies that boundaries knowledge (knowing) through boundaries vision impacts on the creativity and innovation of people and organizations. In other words, the book shows that boundaries knowledge (knowing) brings about capabilities to achieve optimized solutions and processes for innovation activities entailed in the challenge of creating new knowledge taken up by people or organizations, or to find solutions to the problems and issues that they face.

\section{SYNERGIES BETWEEN CORPORATIONS AND EXTERNAL ENVIRONMENTS}

In the view of strategic management as a dynamic process, corporate systems (capability factors in a company such as strategies, organizations, technologies, operations and leadership) must change dynamically to adapt to dynamically changing environments surrounding corporations (markets, technologies, competition and cooperation, structures) (Kodama, 2010a). The boarders or corporate boundaries between environments and corporate systems define the relationships with environments and company business models (Kodama, 2009b, $2018 a, b)$. Changes in environments bring about changes in corporate boundaries and simultaneously affect individual elements of capabilities in corporate systems. Conversely, changes to 


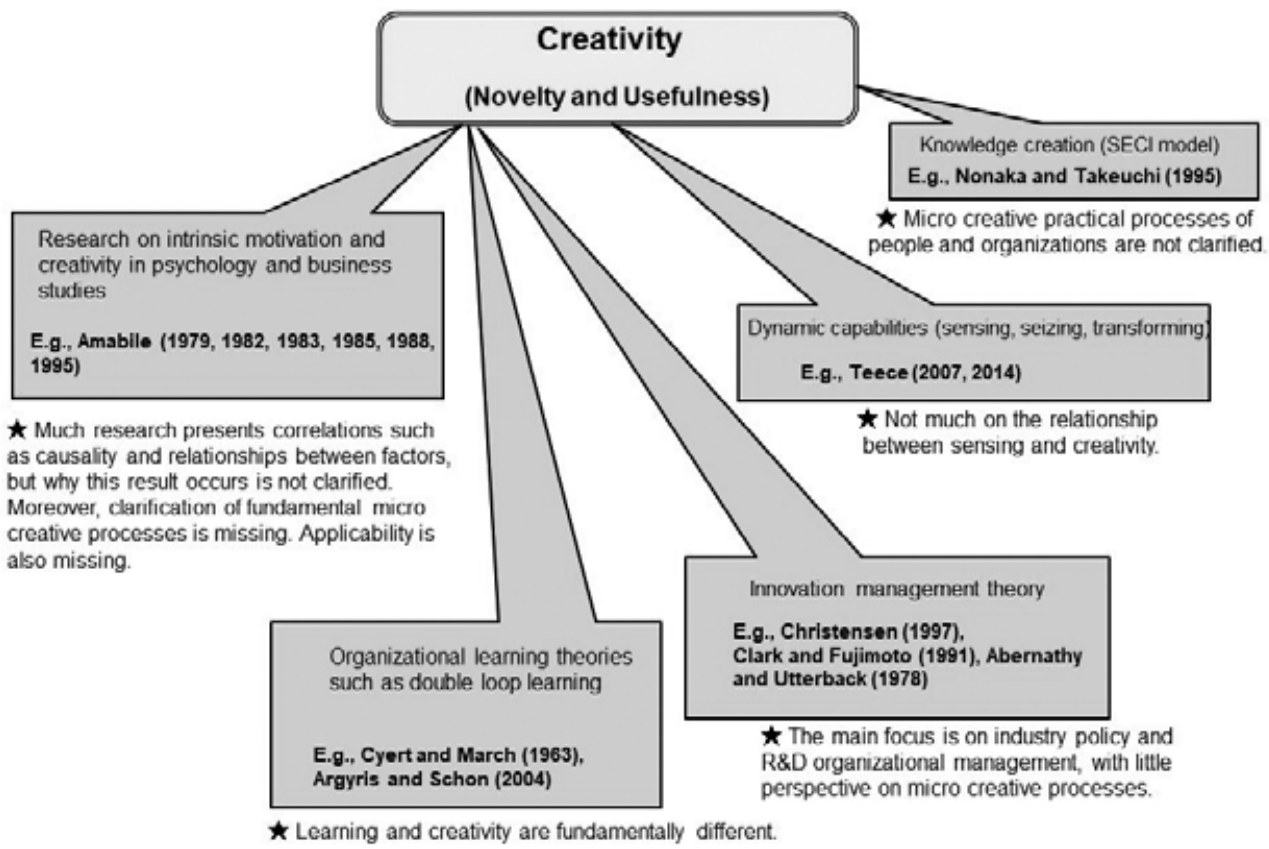

Figure 1.1 The creativity-themed field of existing research

the individual capabilities in corporate systems (either active or passive) bring about changes to the corporate boundaries of a company, and in turn also affect the environment.

Teece (2007) argues that the activities of coordination and resource allocation by managers form markets (environments, ecosystems) in the same way markets (environments, ecosystems) form corporations. In other words, companies and markets are in co-evolution relationships (see Figure 1.2). Thus, good asset orchestration by managers with technical fitness (DC, dynamic capabilities) enable a company to create favorable external environments, which as a result ties in with raising "evolutionary fitness" (Helfat et al., 2007).

Also, Teece (2007) states that in a multinational enterprise, one of the core functions of management is to develop and implement the company's unique strategies, which means they must "fit" assets, structures and processes globally (and their individual internal elements), and the company management team must also decide or uncover the technological opportunities and customer needs the company is facing while securing the resources and assets needed to execute strategy. Hence, the capabilities to proactively adapt, redeploy, and reconfigure in an entrepreneurial fashion gives meaning to "orchestration" and thus to "dynamic capabilities".

Interpreted differently, this could be a company establishing and executing an "environment adaption strategy" to adapt to environmental changes, or could mean a company establishing and executing an "environment creation strategy" to create new environments by acting dynamically on environments (ecosystems). Thus, practitioners in companies have to inten- 
tionally change business factors related to capabilities of strategy, organizations, technologies, operations and leadership in corporate systems to bring congruence to the boundaries between capabilities elements. This means that both the capabilities congruence between corporate systems and markets (ecosystems) (dynamic external congruence) [Insight-1] and capabilities congruence between capabilities in corporate systems (dynamic internal congruence (congruence between subsystems)) [Insight-2] are required (Kodama, 2018a, b). The function that achieves capabilities congruence both in and outside of companies is asset orchestration through dynamic capabilities (DC) (see Figure 1.2).

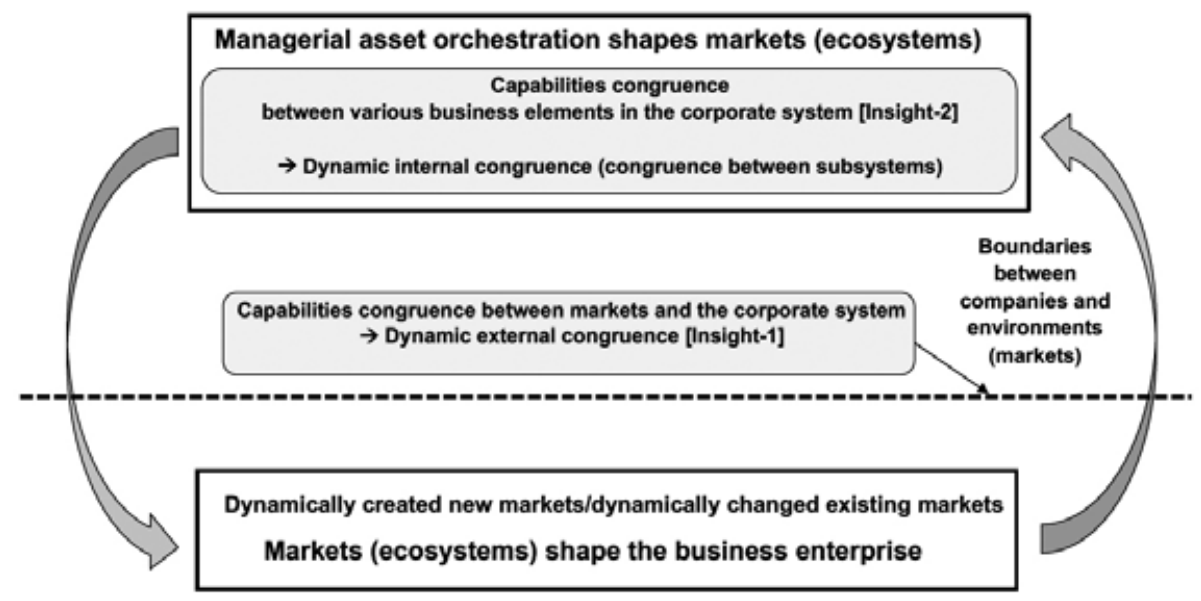

Figure 1.2 Capabilities congruence inside and outside of companies

Firstly, this chapter discusses elements of dynamic capabilities for capabilities congruence between corporate systems and markets (ecosystems) (dynamic external congruence) [Insight-1]. The three crucial elements of sensing, seizing and transforming required for successful organizational adaption are identified in the dynamic capabilities framework (Teece, 2007, 2014). Companies equipped with dynamic capabilities enact organizational transformation required to maintain superiority by sensing business opportunities ahead of the competition and utilizing them more effectively. Dynamic capabilities directed through a clear strategic vision enable companies to adapt to fluid and uncertain situations.

Day and Schoemaker (2016) deductively extracted the six sub-capabilities that comprise dynamic capabilities from existing theories on best practices. Figure 1.3 shows the comprehensive cluster relationship between sensing, seizing and transforming advocated by Teece (2007) and the six sub-capabilities. The chapter outlines the DC sub-capabilities of Day and Schoemaker (2016), and then presents the three new sub-capability elements proposed in this book. 


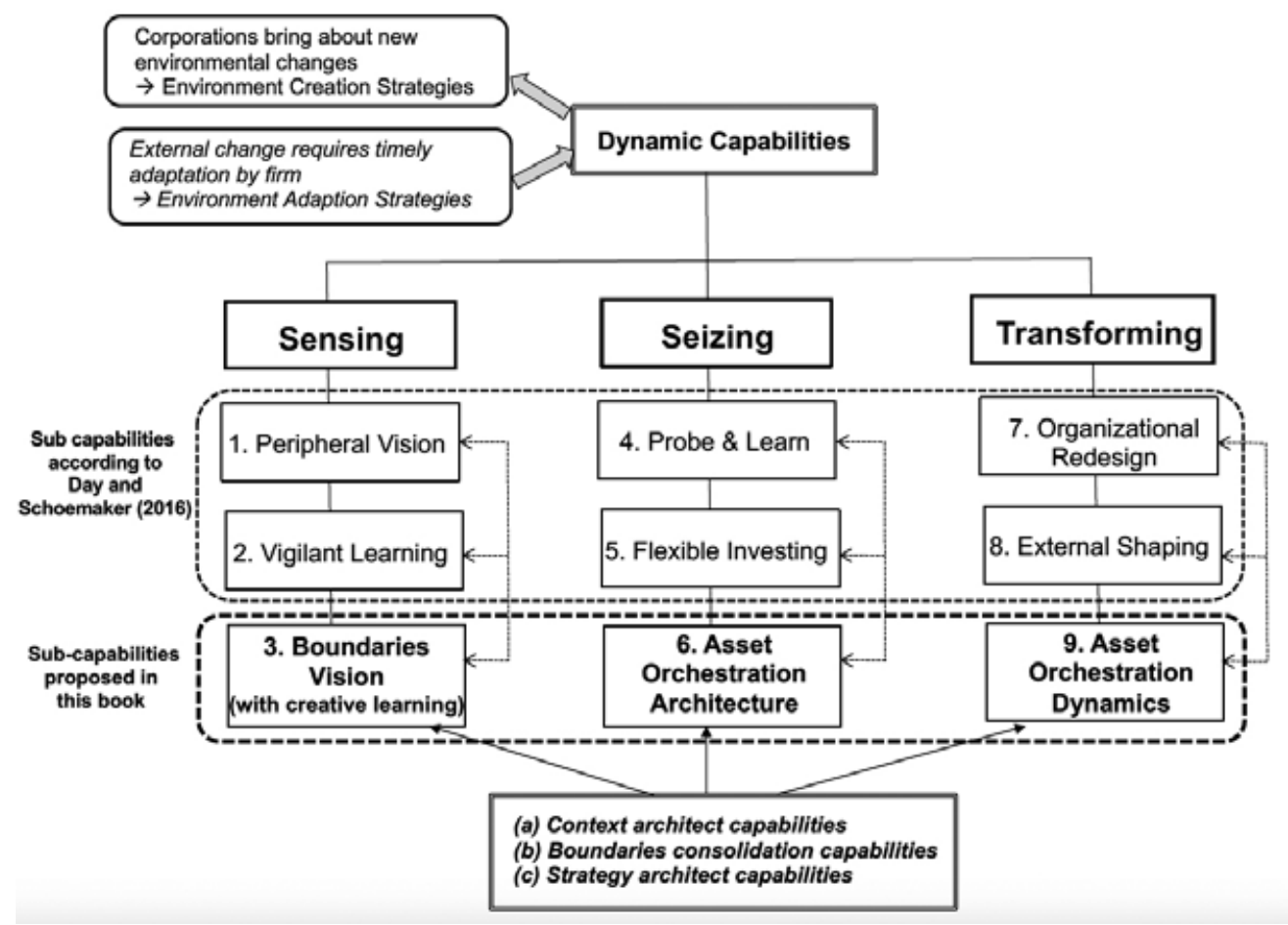

Figure 1.3 The framework of this chapter in contrast to Teece (2007) and Day and Schoemaker (2016)

\section{DC SUB-CAPABILITIES}

\subsection{Sensing in Fast-Changing Environments}

According to research by Day and Schoemaker (2016), sensing leading to success can be understood through two mutually related learning processes that function as DC. These two processes are peripheral vision (sensing faint signals from business boundaries) (Day and Schoemaker, 2005) and vigilant learning (correctly interpreting the meaning of the faint signals that arise).

\subsubsection{Peripheral vision}

There are greater requirements on this sub-capability than analysis of the influence of trends identifiable through the foresight activities often undertaken by companies. The purpose of peripheral vision is to distinguish the early signs of latent opportunities or threats ahead of the competition. Just like human vision, there is a fuzzy zone in the periphery away from the focal point. In this area, it is difficult for companies to see and scrutinize peripheries due to the adverse effects of the signal-to-noise ratio. Information overload, intelligence dispersal and confusion are major impediments to improving peripheral vision. The two important steps 
of setting a scope and scrutiny are required to overcome these difficulties and acquire strong peripheral vision.

\subsubsection{Vigilant learning}

The process of sensing changes in the external environment begins with scrutinizing faint signals. The second sub-capability of sensing requires exploratory and vigilant interpretation of signals. In this context, vigilance refers to a state of heightened awareness and curiosity, and is characterized by alertness, curiosity and proactive reactions to fragmented information. Rapid learning requires a strong market-oriented attitude, attention on people for filtering, suppression of biases, and a triangulated perspective on complex issues.

\subsection{Seizing: Developing Opportunities}

Once a company senses initial changes occurring in the environment and understands some of its profound implications, the next question is what to do with the new knowledge gained. Then, at the same time as action and commitment arrive on the scene, the very real risks of pursuing reckless strategies based on incomplete or biased information must be dealt with.

\subsubsection{Probe-and-learn experimentation}

Small, well-designed experiments to investigate new strategic initiatives enable continuous investment that is most likely to lead to positive results. For example, rapid prototyping with quasi-experimental designs can be very useful for complex design decision-making. Leading companies raise the level of these practices to DC implementable across many fields.

In trial and error learning, leaders need to actively nurture and support cultures that tolerate, and in some cases encourage, failure. Although failure due to carelessness or neglect should be avoided, no organization can learn by pursuing a policy of zero tolerance for failure. It is important to allow and learn from failure and to develop a culture in which experimentation is the norm.

\subsubsection{Deploying real options}

Trying out different approaches, exploring incomprehensible challenges in detail, and staying alert to unexpected situations are all great ways to learn quickly. Companies devise a range of real options to respond to various degrees of technology and market uncertainty. Crucially, successful companies need to develop a portfolio of different options (for protection and conservation, procurement and exploration) because the objectives are different for each type of option.

\subsection{Transforming: Internal and External}

Although sensing and seizing create business opportunities for a company, for a company to properly implement a new strategy, it must be able to steer the external environment as well as have the ability to form environments in addition to the ability to adjust its internal organizational design. A transformative organization is an organization that actively nurtures agile and entrepreneurial thinking and has a broad approach to building networks outside of itself. 


\subsubsection{Organizational redesign}

New strategic initiatives may or may not succeed depending on how organizations are separated. The degree of their independence required in each case depends on the magnitude of the technology discontinuity, the speed of change and whether the value of the competencies in core businesses is reviewed with new strategies.

\subsubsection{External shaping}

Transformative power includes not only internal redesign, but also renegotiation with the environment to form a corporate ecosystem, which can be done through joint lobbying, development of new industry standards, and redevelopment of corporate business ecologies. Business ecology redevelopment can result in particularly powerful changes because it relies extensively on external networks.

The corporate ecosystem can act as a strategic radar system, and using these networks at multiple touchpoints can catch faint signals and speed up the sensing process.

\subsection{The New DC Sub-Capabilities Proposed in This Book}

In contrast to the six DC sub-capabilities of Day and Schoemaker (2016) outlined above, this book presents the elements of "boundaries vision", a new peripheral vision, "asset orchestration dynamics" and "asset orchestration architecture" as further sub-capabilities.

\subsubsection{Boundaries vision}

\section{(a) Knowledge boundaries}

In the knowledge economy, diverse human knowledge (of which technology is one element) is the source of valuable products, services and business models that can give a company new competitiveness. New value chains are formed as new strategic models by converging diverse technologies and different industries to bring about new products, services and business models that transcend various boundaries (Kodama, 2014). Accordingly, for companies to build new businesses, they must refresh their perspectives on business across the boundaries between the knowledge of individuals, groups and organizations.

Technical convergence, in other words "knowledge convergence", has become crucial for successful new innovation across different areas of specialization (e.g., Klein, 1990; Porter and Teisberg, 2006). New innovation happens by bringing together the unique knowledge of different types of specializations and the technical convergence process (e.g., Kodama, 2005a, b, 2009a, b; Hacklin et al., 2009; Rafols and Meyer, 2010), in other words, the knowledge convergence process can be thought of as operating on a level straddling different specialist fields. Convergence of knowledge that once belonged to separate areas of technical expertise is essentially the precondition for technical convergence. Therefore, to make technical convergence occur, it stands to reason that knowledge convergence across different areas of technical expertise is required.

However, knowledge boundaries (Carlile, 2002) generally exist between dissimilar types of knowledge. This means unique differences with dissimilar characteristics and details exist between different types of knowledge. For example, a corporation is divided into various functional organizations and specialist fields, and various business types and functions are separated from each other between corporations and industries, and among all these, from the 
macro to the micro levels, many visible and invisible boundaries exist. In corporations, practitioners do not only face the organizational boundaries as sectionalism, but also the knowledge boundaries that exist at the micro levels as a result of their values, backgrounds and areas of specialization (see Figure 1.4). These various knowledge boundaries isolate the unique mental models and path dependent knowledge of practitioners, and are a hindrance to new innovation (e.g., Spender, 1990; Kogut and Zander, 1992; Leonard-Barton, 1995; Nonaka and Takeuchi, 1995; Brown and Duguid, 2001; Carlile, 2002).

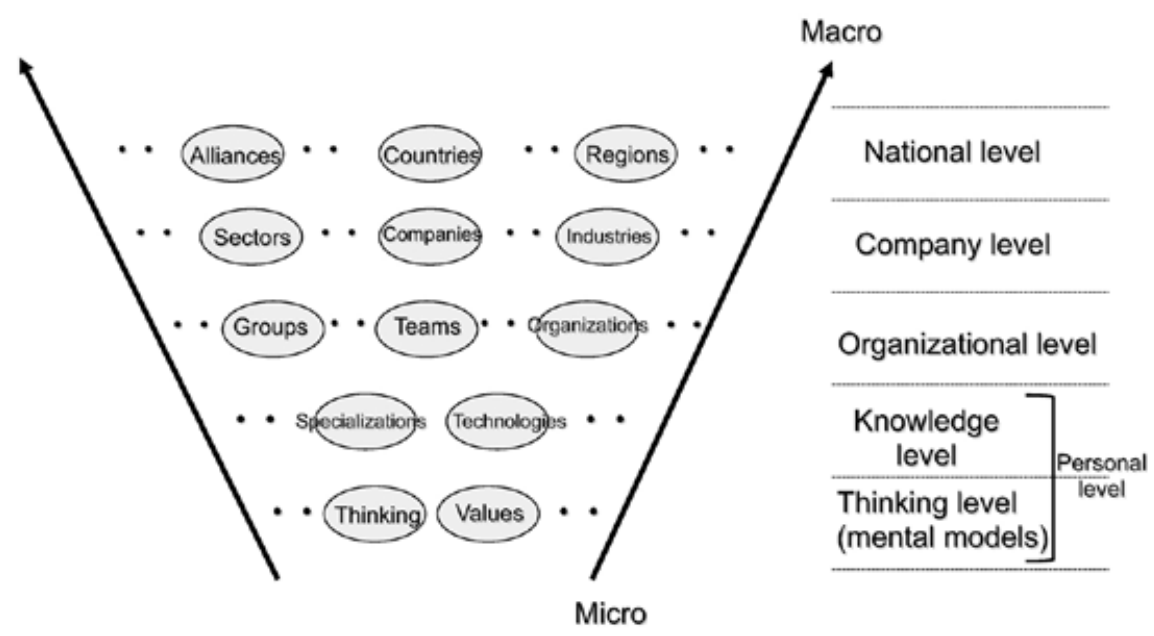

Figure $1.4 \quad$ Existing various boundaries

Furthermore, as the novelty in circumstances surrounding individuals, organizations or companies or knowledge boundaries between different types of knowledge become more pronounced, both quality and quantity of knowledge boundaries also expands (or rises) (Carlile, 2004). However, to date, most of the new knowledge creation that has come about with innovation has been shown to have occurred on the boundaries between different specializations (e.g., Leonard-Barton, 1995; Nonaka and Takeuchi, 1995; Kodama, 2007a, b). This suggests that the thinking and ideas between people and the actions of organizations straddling different fields of specialization are major factors in bringing about innovation success, and therefore factors that contribute to competitive excellence.

In contrast, existing research also clarifies why it is difficult to generate and maintain innovation (Leonard-Barton, 1995; Carlile, 2004). Also, it has been reported that the ideas of people and actions of organizations straddling different fields of specialization are constrained by knowledge path dependency (March, 1972; Rosenkopf and Nerkar, 2001). For example, traditionally it was recognized as easier to concentrate exploration for innovation in closely related specialized fields. However, deep communication and collaboration processes between different fields of specialization have also been reported to contribute greatly to new innovations (e.g., van Rijnsoever and Hessels, 2011). Thus, to encourage this kind of communication and collaboration, the way the knowledge boundaries perceived by individuals and organizations are uncovered and tied to hints that will lead to new innovation is critical. In short, this 
is the capability required for practitioners to grasp whether the dissimilarities and differences on diverse boundaries will be a source of new knowledge convergence (Kodama, 2014) (or new knowledge creation). Generally, most people feel uncomfortable when facing unfamiliar boundaries (boundaries of different contents to which they are unaccustomed), and different people have different perception and recognition capabilities at the boundaries where such discomforts occur.

Moreover, many practitioners recognize that there are "unseen walls" in complicated business settings that straddle businesses and areas of specialization in companies, and between organizations including customers. The problems and issues that relate to new business in relationships with external partners and customers are further complicated by the far greater degrees of tension that exist in the contexts inside a company. So, how can we manage the knowledge possessed by various practitioners to create new knowledge by transcending organizational and knowledge boundaries? The capability that drives recognition and perception of these various boundaries, and triggers the convergence of dissimilar knowledge is "sensing through boundaries vision", as described as follows.

\section{(b) Sensing through boundaries vision}

As discussed earlier, sensing is the ability to seek out business opportunities and filter and analyze them, and is dependent on the cognitive capabilities of individual practitioners such as leading organizational members mainly in managerial layers. In the process of selecting new technologies and $R \& D$ with innovation, the cognitive capabilities of management layers are of extreme importance for appropriately responding to dynamic external environments or business opportunities.

In recent years, Helfat and Peteraf (2015) have discussed how differences (heterogeneity) in the cognitive capabilities of top manager teams bring about disparities in organizational performance in changing situations. According to their reviews of the theories of cognitive psychology, cognitive science, social psychology, cognitive neuroscience and behavioral decision theory, cognitive capabilities entail important aspects that are fixed to certain contexts or areas. They argue that existing research (e.g., Ericsson and Lehmann, 1996) suggests that these aspects can affect heterogeneity in cognitive capabilities.

Helfat and Peteraf (2015) assert that cognitive capabilities, the foundation for these mental processes (or mental models), has been considered as an important attribute in managers at the top of organizations in many years of research into management, and present a number of cases of evidence such as research by Rosenbloom (2000) into NCR, and research by Tripsas and Gavetti (2000) into Polaroid. Furthermore, they also suggest that top managers should strengthen "paradoxical cognition" (Smith and Tushman, 2005) to be able to pursue exploration and exploitation (March, 1991) simultaneously, and at the same time they warn that empirical knowledge of the past may bring about hindrance by unwittingly and inappropriately relying on specialist knowledge of the past when companies search for new technologies and strategies (Miller and Ireland, 2005). As confirmed by existing research into the field of management, heterogeneity in the cognition of top management teams affects the heterogeneity of approaches to strategic change and their outcomes.

However, the role played by the cognitive capability of the intuition of leading practitioners is large, and gives them awareness and flashes of insight brought about by interactions with a wide range of stakeholders (including customers and partners). To demonstrate the cognitive 
capability of intuition, practitioners must have the capability of boundaries vision (Kodama, 2011; Kodama and Shibata, 2016) to be able to acquire new insights from complex and diverse boundaries. The concept of boundaries vision is a new proposition that entails dissimilar knowledge integration capability - the ability to orchestrate dissimilar intangible assets (see Box 1.1), boundaries architecture - the corporate design to achieve new business models by defining new corporate boundaries by integrating dissimilar boundaries, and boundaries innovation - the process of innovation across the boundaries between companies and even industries (Kodama, 2009a) and so forth (Kodama, 2011).

"Peripheral vision" is what is required for dynamic vision and sensitivity to stay ahead of speedy environmental changes. Driving peripheral vision enables risk management and acquisition of opportunities without missing signs to survive in an era of change. Boundaries vision in Figure 1.3 encapsulates the concept of "peripheral vision".

Boundaries vision is not only the engagement of peripheral vision limited to the periphery of a company's main business domain, but also includes the business domains of different industries across diverse boundaries previously unrelated to the company (or in which the company had no interest). Figure 1.5 shows the differences between peripheral vision and boundaries vision.

Boundaries vision does not only mean a view of the fuzzy zone of the peripheral area that cannot be easily exposed by the light of a flashlight or laser. Boundaries vision is more like an omnidirectional camera. An omnidirectional camera has two lenses, one at the front and one at the rear. Each lens covers those respective views, and the images of the two lenses are combined to give a $360^{\circ}$ view from the ground to the sky. Omnidirectional cameras are able to capture $360^{\circ}$ panorama images in all directions, up down, right and left, or even $360^{\circ}$ video, and are also called $360^{\circ}$ cameras, VR cameras, or full dome cameras.

As discussed, it is necessary to engage in "vigilant learning" to demonstrate peripheral vision, although to demonstrate boundaries vision, creative learning is also a crucial element, as discussed later (see Figure 1.3). However, boundaries vision and peripheral vision are in a complementary relationship with each other and must be used accordingly to respond to the environments and situations, etc. facing companies.

In his fieldwork to date, the author has recognized patterns of action based on network thinking characterized by boundaries vision, which practitioners use to bridge the diverse boundaries both in and between companies, to share knowledge, and to create new knowledge. Boundaries vision is the insights and thinking that practitioners have and use to design new business and corporate strategies through asset orchestration by recognizing and bridging diverse boundaries.

Put differently, boundaries vision means the capability of practitioners to seek out various differences and discomforts on boundaries and from them uncover whatever new knowledge, such as hints or ideas, are available. Boundaries vision is also the capability to figure out what types of boundaries are discovered and how to link them together to trigger new knowledge as new ways of perceiving or discovery of new things ("boundaries knowledge" discussed in detail in Chapter 2). Boundaries vision is not static, but is a dynamic, constantly changing capability. For individual practitioners and organizations, training and demonstration of boundaries vision is an essential source of new knowledge convergence, and similarly, boundaries vision is the most fundamental element for convergence of dissimilar knowledge. 
[Focus on peripheral vision]

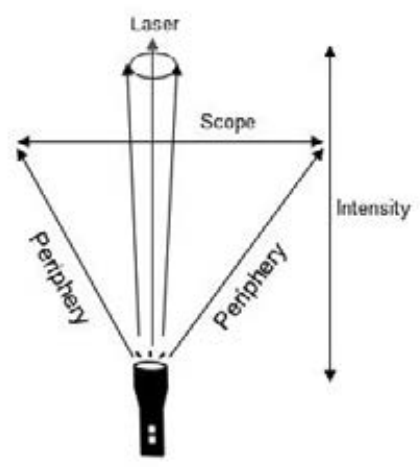

Flashlight/laser
[Focus on boundaries vision]

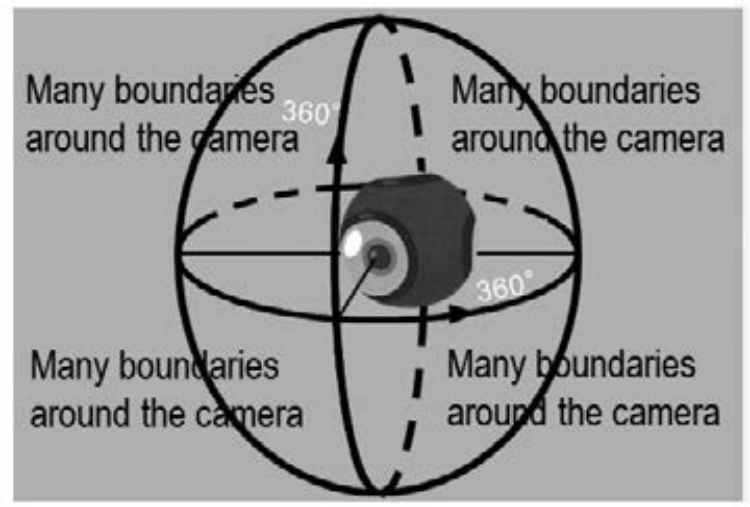

Omnidirectional camera

Source: Day and Schoemaker (2004, Figure 1).

\section{Figure 1.5 Difference between boundaries vision and peripheral vision}

To achieve knowledge convergence dynamically on diverse and multiple boundaries, practitioners must demonstrate boundaries vision, and bring about external knowledge convergence capabilities: the cognitive capabilities to converge dissimilar knowledge (see Box 1.1) to achieve new products, services and business models. In practice, managers have to focus on various boundaries and use their "external knowledge convergence capabilities" to bring about new innovation through the convergence of dissimilar knowledge.

External knowledge convergence capabilities through boundaries vision are capabilities beyond peripheral vision for detecting dissimilar knowledge that is only loosely related or entirely unrelated, and uncovering relationships with one's own knowledge and converging it with that knowledge. Much of the existing research to date has already reported that the crossing or fusing of dissimilar knowledge is a source of new innovation (e.g., Johansson, 2004). Accordingly, for practitioners, being able to uncover relationships between a variety of dissimilar or existing knowledge, and discovering new meaning in those relationships, is an important initial trigger to demonstrate external knowledge convergence capabilities.

When practitioners have little experience (for example when joining a company in their younger years), as their mental models, their thinking frameworks are restricted to specific tasks and routines in the workplace. Then, as they accumulate empirical knowledge and work in various specialties or job functions, they come to know and understand various thinking frameworks and relationships between dissimilar knowledge. The author describes these concepts as "shared thought worlds" and "harmonized knowledge" respectively (Kodama, 2007b; Kodama and Shibata, 2014). However, the deeper practitioners in certain specialist jobs (for example, researchers or specialist engineers) go into the area of specialty, the higher 
the probability that they will be unable to escape from the thinking framework they have built on such particular knowledge (e.g., Kodama, 2007a).

In contrast, innovative and humble practitioners tend to have a strong tendency to perceive things beyond the framework of their own specializations, professions, organizations, companies or industries. These people understand mental models and thinking frameworks different to their own, and constantly learn to absorb dissimilar knowledge (e.g., Kodama, 2007b). It is the core human abilities of innovative practitioners that enable them to subjectively bring about new knowledge. In particular, to converge knowledge by external knowledge convergence capabilities through the demonstration of boundaries vision, "creative learning" (e.g., Kodama, 2007a, b) and collaboration is required among practitioners by forming human networks that span in and between organizations (and between companies) (e.g., Tushman, 1977; Owen-Smith and Powell, 2004; Lin and Kulatilaka, 2006). The organizational platforms required to form networks to bring about this creative learning are called "strategic communities” (SC hereinafter) (see Box 1.2) (e.g., Kodama, 2002, 2005a, 2009a).

\section{BOX 1.1 EXTERNAL KNOWLEDGE CONVERGENCE CAPABILITIES THROUGH BOUNDARIES VISION}

As Herbert Simon $(1996,1997)$ pointed out, human cognitive faculties have their limitations. Hence, humans built the world of multilayered organizations and functionally separated management. Simon described "limited rationality" to illustrate the limits of human cognitive and information processing capabilities which include the limits of rationality and cognition. In other words, there is a limit to how much information humans can process, and human beings can never be completely rational. In answering the question of why human beings form organizations, Simon argued that within a certain limited scope, objective and rational judgments can be made, and the organization is a social device that enables shrinking of the complexities of the world by restricting such scope to within the limits of human cognition. Thus, by forming the layer structures of organizations, the complexity of decision-making can be distributed across subsystems (or modularized). In this way, Simon asserts that high-level decision-making can be performed that would otherwise be impossible for individuals.

Certainly, corporate activity consists of a wide range of business processes (basic research through to applied research, marketing, product development, manufacture, sales, distribution and after sales services, etc.), and there are many diverse contexts in which businesses operate. There really is not any one person in any company who has all the basic skills needed to perform every task from R\&D for new product and services through to sales and support (or even if there are, they are very few).

To create concepts for excellent new products, services and business models, and implement these, strategic communities (SC) and networked SC as multilayered SC formations are indispensable, and in these $\mathrm{SC}$ there must be such mechanisms with which practitioners in core departments in new product development such as marketing, R\&D and production create and share dynamic contexts across the boundaries of organizations. This enables practitioners to create and put into practice new knowledge (business concepts for new products and services, etc.).

Individual practitioners in departments have diverse and unique world views and values. 
Patterns of behavior and thinking as certain paradigms based on past experiences (with jobs or specialist technologies in various departments such as marketing, R\&D and production) lie at the root of the way an individual lives. For example, practitioners in charge of marketing engage in "dialectical synthesis" (Kodama, 2007a) through the synergy of their own subjective perceptions (a viewpoint to uncover latent demand by assimilating with customers) and objective perceptions (analysis of competing products and customer data) to unceasingly create new recognition such as "we have to plan products that will provide customers with new value", or "how do we grasp the latent needs of customers to plan such products?" However, that does not mean that they have absolutely no technical perspective. These practitioners are always keeping an eye on technical trends both in and outside of their companies, and making efforts to verify concepts of latent usage systems that customers themselves would probably not notice, while always bearing in mind that although there are many uncertainties, if they can bring about a particular technology it will be possible to provide customers with new functions and services.

In contrast, practitioners in $R \& D$ and production departments engage in dialectical synthesis through the synergy of their own subjective perceptions (thoughts and beliefs about what they want to develop) and objective perceptions (concentration and selection based on analysis of technical trends and benchmarks of other companies' technologies) to unceasingly create new recognition such as "we have to develop technologies that will satisfy customers", or "we have to develop core technologies that competing companies can't imitate". Nevertheless, that does not mean that engineers have no idea about markets. Certainly, engineers can make proposals to customers from their own seed-oriented ideas about what is possible.

Thus, practitioners in various departments proactively form multilayered SC in their companies, and as their subjectivities clash from market and technology contexts and perspectives they collide with these paradigms, bring about new energy and create contexts with a higher dimension. Practitioners come to understand each other's diverse world views and values, and bring about mutual recognition and new rules through creative and dialectical dialogue, and creative learning between different organizations. However, as practitioners mutually understand and share their thoughts and feelings, they combine both assertiveness and humility, and question how to create new knowledge. This enables individuals to develop in the dimension of higher thoughts and ideas. These are "external knowledge convergence capabilities" - abilities to generate and achieve new business concepts by synthesis of dissimilar knowledge through "abduction" (Peirce, 1998) (see Figure 1.6). Practitioners' external knowledge convergence capabilities are the driving force behind the achievement of knowledge convergence. 


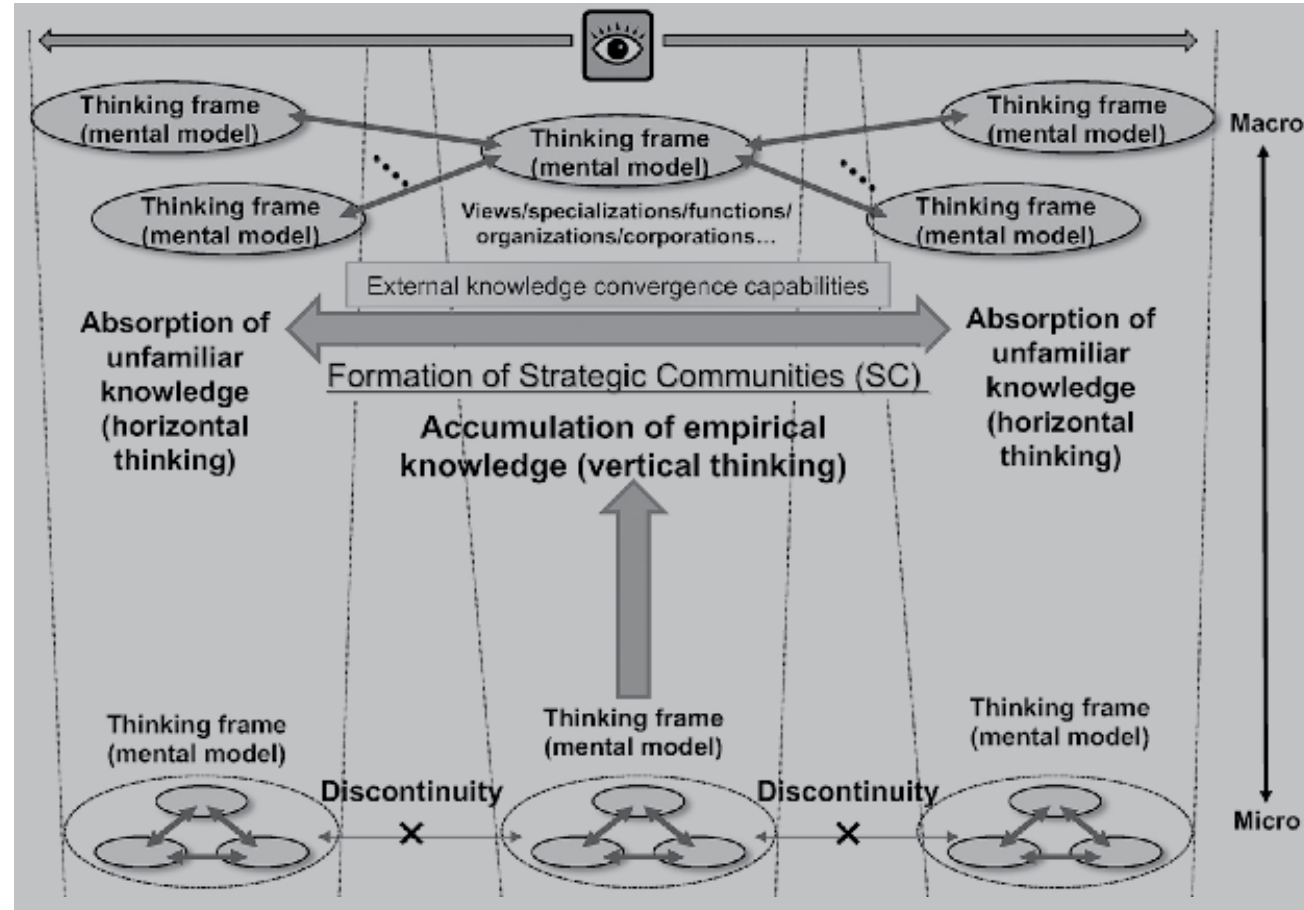

Figure 1.6 External knowledge convergence capabilities through boundaries vision, demonstration of boundaries vision

\section{BOX 1.2 FORMING STRATEGIC COMMUNITIES (SC) TO BRING ABOUT EXTERNAL KNOWLEDGE CONVERGENCE CAPABILITIES}

\section{The Characteristics of "ba" and "Small-World Networks" (swn)}

SC have the quality of "ba" (Nonaka and Takeuchi, 1995; Nonaka and Konno, 1998), and are defined as follows (Kodama, 2005a, p. 28):

Strategic communities are based on the concept of "ba" as shared spaces for emerging relationships that serve as a foundation for knowledge creation. Participating in a ba means transcending one's own limited perspective or boundaries and contributing to the dynamic process of knowledge creation. In a strategic community, members (including customers) with different values and knowledge consciously and strategically create a ba in a shared yet constantly changing context. New knowledge and competencies are formed by the organic merging and integrating of communities to form new ba to address multiple new eventualities. From the practical aspect, we see the strategic communities as informal organizations possessing elements coherent with both the resource-based view of emergent shared-context learning and the planned strategic-based view of planning for a targeted market position. 
Furthermore, Kodama (2009a, p. 469) asserts that SC have the characteristics of the "small-world structures" of network theory, described as follows:

SC are groups forming small-world structures where practitioners in diverse specialisations realize innovations to solve the issues facing them and implement problem-solving and creative strategies. Short connections between nodes (people are the first unit nodes) and local clustering are features of small-world structures. For example, short paths among nodes of practitioners belonging to different organisations enable easier access to other practitioners within a firm or based in other firms, including customers. Each node in a small-world structure is embedded in a local cluster. This clustering then enhances the possibility of fostering reliable accessibility. A small-world structure can be formed by either randomly rewiring a portion of an existing regular network or attaching each new node to a "neighbourhood" that already exists.

In this way, SC have the small-world structure characteristics of ba or networks.

\section{SC Driving Collaborative Activities through Creative Learning}

In practice, SC have the characteristics of "pragmatic boundaries" (Carlile, 2004). For example, Kodama (2005b, p. 40) asserts that SC plays the following role in real business activities:

Boundaries. The third principle is that the SC provides pragmatic boundaries, allowing actors with different contexts to transform existing knowledge. A variety of problems or issues are posed in the pragmatic boundary, and actors face the challenge of solving these problems and issues by creating new knowledge. The actors of an organization thus have to engage in practical yet creative confrontations or conflicts and also political negotiating practice. Innovation and creativity emerge on the boundaries between the disciplines and specializations of different organizations.

In other words, to bring about creativity, creative learning by dialogue and practice through creative confrontations and discord among members is necessary.

In addition, Taifi and Passiante (2012, p. 2125), who discussed "new products and service development through strategic community creation", stated the following about the importance of SC formation.

The case study provides and analyzes the structuring characteristics and success factors of an SC of after-sales services firms in the automotive sector. The study shows that it is important to have entities - more precisely SC - dedicated to the after-sales services firms for the integration of their technical knowledge in the innovation process. The SC plays the key role of contributing to the development of both the products and the services of the automaker. The paper contributes to the literature on the SC, which is one of the most important entities of inter-organizational collaboration and innovation.

In other words, integration (convergence) of knowledge through collaboration between companies is crucial for service innovations.

Looking at this existing research, SC can be called "organizational platforms" for evolving core knowledge both in and out of companies while actively searching for the best knowledge from around the world and converging it with the core knowledge in the company. How do practitioners form SC and create new business concepts in companies that bring about a competitive edge through such knowledge convergence? 


\section{(3)}

\section{Forming Strategic Communities with Boundaries Vision}

Through boundaries vision, practitioners must leverage their external knowledge convergence capabilities and build SC in and out of the companies. Boundaries vision, the foresight of practitioners to achieve asset orchestration, is also the capability to obtain new insights into the complicated and diverse boundaries that exist both within and outside of companies and organizations. Boundaries vision is the ability to create assets (knowledge) through external knowledge convergence capabilities, redefine corporate boundaries and promote radical innovation to achieve new products and business models, as well as drive incremental innovation for existing business. The process of dynamically changing corporate boundaries and combining incremental and radical innovation by exploration and exploitation activities through the building of asset orchestration architecture (described in section 3.4.2) is "asset orchestration dynamics", the "transforming" sub-capability (described in section 3.4.3).

It is important that practitioners in companies have a perspective on creating new assets (knowledge) by the boundaries vision of individuals, groups and organizations to achieve asset orchestration dynamics to simultaneously grow existing business and create new markets through incremental and radical innovation. For this reason, it is necessary to embed the spiral dynamic process of demonstration of external knowledge convergence capabilities through boundaries vision (sensing) $\rightarrow$ building asset orchestration architecture (seizing) $\rightarrow$ and achieving asset orchestration dynamics (transforming). Through the synergies between external knowledge convergence capabilities by boundaries vision and asset orchestration architecture, practitioners converge (orchestrate) different and diverse knowledge needed to achieve their corporate visions and strategic objectives, and through recursive processes, continually bring about new assets (knowledge). This is also the "dynamic capabilities framework" triggered by boundaries vision (see Figure 1.7).

Strategic communities (SC) play the role of dynamically achieving asset orchestration dynamics both in and out of companies across the company internal (people, organizations, different specializations, etc.) and external boundaries (between companies, between companies and customers, and between different industries, etc.). 


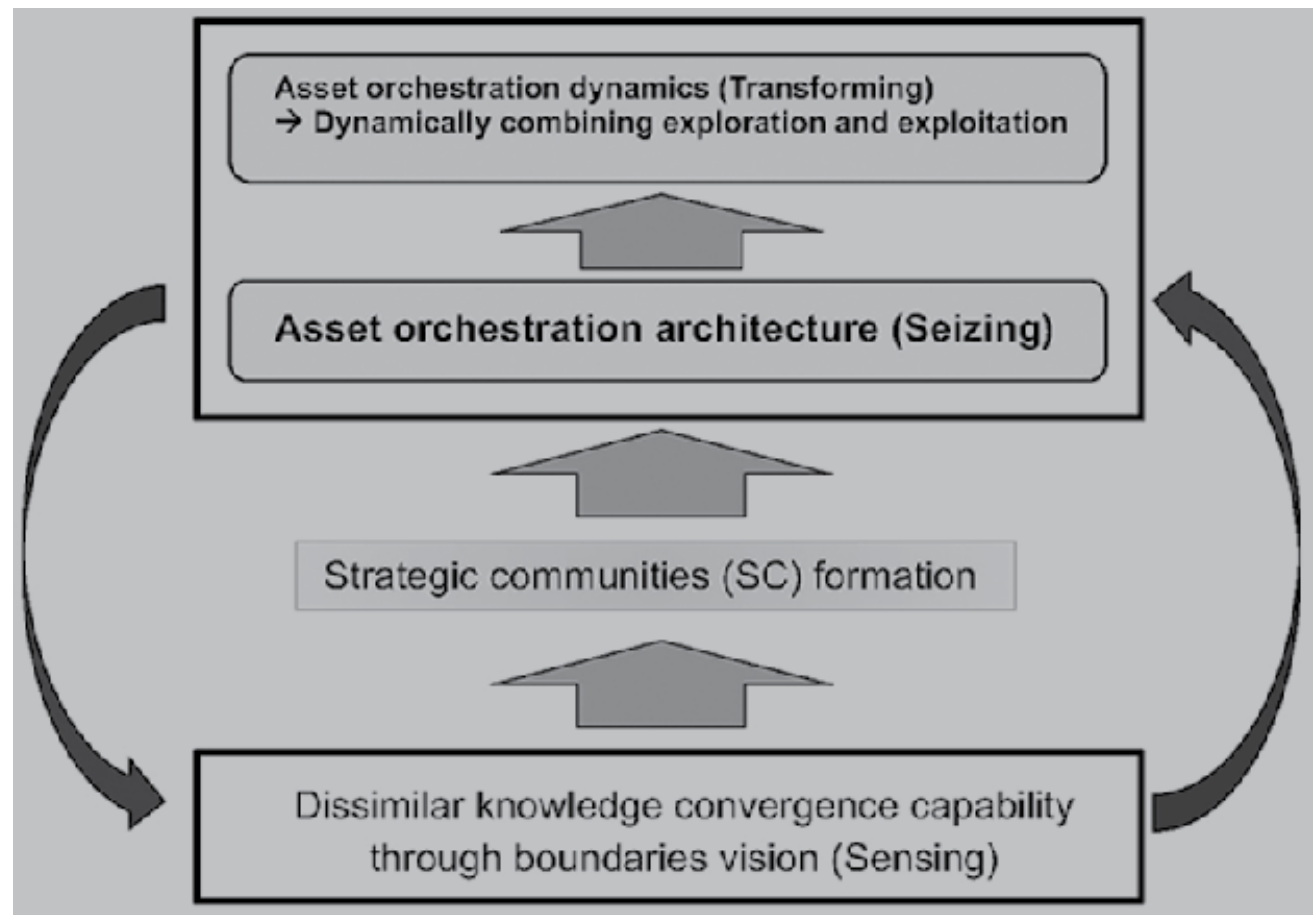

Figure 1.7 DC framework-perspective from boundaries vision

\subsubsection{Asset orchestration architecture}

\section{(a) Seizing through asset orchestration architecture}

Recently in many countries, it has become necessary to design open innovation (Chesbrough, 2003) to expand the scope of searches for business opportunities through joint research systems between industry, government and academia that transcend the boundaries between corporate organizations and enable leading middle managers and top management teams to cooperate with suppliers to grasp customer needs and bring in the best technologies from the outside or hybrid innovation, an intermediate between open and closed innovation (Kodama, 2011), to bring in the best technologies from the outside. In the aforementioned era of convergence, important managerial considerations include new knowledge about the dynamic strategic processes of configuring new business models with practitioners using their boundaries vision to draw up grand designs for new asset orchestration architecture (see Box 1.3).

Managers have to face these issues in their strategic thinking and actions as they focus on diverse boundaries to orchestrate different intangible assets (and co-specialized assets) (Teece, 2014) to bring about innovations. Recently, the best core technologies of the world's cutting-edge businesses are becoming dispersed and diffuse across the globe. Accordingly, going forward in this era of convergence, in which valuable co-specialized assets bring about wealth, management that can integrate the best intangible assets spread within and outside of 
organizations including customers (assets orchestration by DC) from multiple perspectives in open systems will become increasingly important. Thus, in the knowledge economy, the concepts of open and hybrid innovation are of major importance to create new products, services and business models through the orchestration of the company's intangible assets (and co-specialized assets) with those of other companies by developing and accumulating competitive intangible assets in a company at the same time as incorporating intangible assets outside of the company.

As discussed earlier, in the sensing process, the demonstration of boundaries vision, which is also the cognitive capability of intuition, is extremely important for leading practitioners to uncover the best intangible assets (and co-specialized assets). Thus, asset orchestration architecture, which is the architecture thinking to analyze and evaluate excellent intangible and tangible assets (tacit and explicit knowledge) and combine these through boundaries vision, a sub-capability of sensing, is required (see Figure 1.3). For example, Apple's foray into the music distribution and smartphone businesses (Kodama, 2011, 2017c, 2018a), and Fujifilm of Japan's foray into the cosmetics business (Kodama and Shibata, 2016) are also the results of the demonstration of (1) boundaries vision and (2) asset orchestration architecture (see Figure $1.3)$.

\section{(b) Developing opportunities by building asset orchestration architecture}

In sluggish (or extremely slow) environmental changes observed at the initial stage of radical innovation, moreover, in highly uncertain environments, a creative process stage for new technology through new ideas, business concepts, discoveries and inventions is crucial. As shown in Figure 1.3, the exploration process is driven by the seizing sub-capability of "probe-and-learn experimentation". There are a wide range of patterns for asset orchestration architecture in such exploration processes (see Box 1.3).

There are many cases of traditional large corporations that have mainly driven closed innovation with in-house research laboratories and development departments under conventional hierarchical systems. Closed innovation is an important process for incremental innovation with path-dependent assets built up over years. In traditional high-tech fields such as the heavy electrical, nuclear power generation, aviation, vehicle equipment, machine tool, medical equipment, semiconductor processing equipment and R\&D machinery industries, closed innovation plays a critical role.

In contrast, in industries such as IT, technologies are rapidly advancing, and the best technical achievements and know-how are becoming increasingly spread out across the globe. In environments which are changing rapidly, asset orchestration through hybrid innovation (Kodama, 2011) to converge and integrate knowledge both inside and outside of companies by adopting open innovation or partially incorporating external core assets is an effective method.

Should a company adopt a vertically integrated model with "vertical integrated architecture" or concentrate on a particular area of specialization with "horizontal integrated architecture" or "linkage relationship architecture"? Should a company look to form partnerships with other companies (with strong or weak ties) to supplement the company's technology, and converge and integrate the strengths of other companies with the strength of the company through collaboration across different business types to build new value chains? Thinking about how to uncover such business models is necessary in the exploration process of this creative stage. Accordingly, practitioners have to concentrate on experiments through trial and error, and trial 
activities while considering the seizing sub-capability of "deploying real options" as shown in Figure 1.3, while allowing for higher diversity of asset orchestration architecture as asset architectural thinking (vertical integrated architecture, horizontal integrated architecture, linkage relationship architecture) (see Box 1.3).

In whatever case, in environments of high risk and uncertainty, companies have to hypothetically test their corporate boundaries in response to strategic objectives or business environments and make attempts at various asset orchestration architecture through these processes of trial and error. If it is advantageous to develop or manufacture in-house, then it is better to engage the company's creativity and configure a vertical value chain model. In contrast, if another company has achieved more with its developments than those in-house, often a company must take the risk of abandoning its development efforts and focus on efficiency through partnerships or mergers and acquisitions (M\&A) to acquire and access external intangible assets. Accordingly, practitioners have to pursue hypothesis testing according to strategic objectives and asset orchestration through diverse asset architectural thinking in asset orchestration architecture in the process of such creative exploration.

Through the subsequent processes of invention, trial experimentation and verification in $\mathrm{R} \& \mathrm{D}$, companies have to set down and execute plans to acquire human resources in-house (or sometimes from outside the company), and streamline and upgrade organizations to incubate the new business of core technologies or business concepts. As such environments surrounding companies shift to more variable environments inside and outside the company, the uncertainty will remain. Asset orchestration architecture in such rapidly changing environments (the speed of external environment such as markets or in-house activities) entails selection of diverse asset orchestration architecture invented, trialed and tested in $R \& D$, which is then raised to a higher level of asset orchestration completion as products, services or business models.

On the other hand, the diversity of factors of asset orchestration architecture - vertical integrated architecture, horizontal integrated architecture and linkage relationship architecture - is lowered with repeated testing and verification processes. Moreover, depending on the situation, sometimes companies review their structural architecture of vertical integrated architecture or horizontal integrated architecture, or review their relationships with other partner companies by changing their linkage relationship architecture.

Thus, through selection by various processes of incubation, and elimination of a certain degree of uncertainty, new businesses with future prospects (including new products, services) shift to business environments with relatively low uncertainty despite changes ongoing outside the company (in the environment) or in-house. In such a business environment for commercialization (business creation), a company determines the management elements (strategy, organizations, technologies, operations, etc.) inside the corporate system by asset orchestration towards the completion of a firm value chain. As a result, the degree of perfection of products and services will be improved. At the stage of commercialization, changes to the factors of "vertical integrated architecture", "horizontal integrated architecture" and "linkage relationship architecture" are lower, and the overall optimization of asset orchestration architecture and related adjustments become the most important issues.

On the other hand, in such commercialization stages, companies must strategically and continually review their business models and raise the level of their technologies to raise the value of their products and services to respond to fast and competitive environments. Therefore, 
as existing products and services are constantly given major upgrades (due to new technical developments or new business models), the need to review asset orchestration architecture arises.

The commercialization stage also includes the original concept of DC to drive incremental innovation, which can be interpreted as the capabilities to generate high performance by the evolution and diversification of operating routines (ordinary capabilities: OC) through high-level learning to generate profits in response to internal and external changes.

In contrast, for many stable existing businesses with their low levels of change and uncertainty and sluggish market environments, companies drive incremental innovation for the thorough efficiency of the business through processes of upgrading and improving existing business (exploitation) with existing organizations (main streams). Asset orchestration with such existing business pursues existing routines and operational efficiency in the framework of fixed and established vertical integrated architecture, horizontal integrated architecture and linkage relationship architecture under continually maintained and precise strategic planning.

As described above, the significance of asset orchestration architecture as seizing is the role it plays in the design of the future when constructing a new business through the orchestration of various assets (knowledge) generated from a boundaries vision that is sensing. In particular, to create new assets by co-specialization, a company needs a unique integration mechanism (difficult for other companies to imitate). This is also asset orchestration architecture.

\section{BOX 1.3 ASSET ORCHESTRATION ARCHITECTURE - ASSET ORCHESTRATION THINKING}

How are SC and networked SC formed, and how are different assets orchestrated through SC and networked SC? The author would like to systemize this based on empirical cases of existing research. This is because the network structures of SC are small-world structures, which determine the patterns of asset orchestration processes. The author would like to present this proposition from design thinking on human networks and organizational networks - in other words, from an architecture perspective, for example, what mechanisms form SC or networked SC in and out of companies? Or, what kind of patterns do practitioners use to form networks? As processes executed through the asset architectural thinking of practitioners, asset orchestration in the cases experienced by the author and other contributors have so far consisted of three general types (vertical integrated architecture, horizontal integrated architecture, linkage relationship architecture) which are divided into two individual models.

In the following, the author describes the research process leading to the derivation of the framework for the architecture of asset orchestration. Regarding the vertical value chain model and linkage relationship architecture, the author analyzed synergies between business activities (the level of vertical integration), the relationship between the transactional relationships between businesses (contract details, contract periods of validity, power relationships, etc.) and the level of knowledge sharing (levels of information sharing, knowledge transfer and collaboration), and value networks in which business models are created. Regarding the multilayered model, the author conducted structural analysis of project organizations in companies. In addition, regarding the horizontal value chain and complementary model, the author analyzed the level of knowledge sharing and processes that lead to 
the formation of business models through joint development and strategic alliances among companies.

\section{Vertical Integrated Architecture}

Vertical integrated architecture means vertically integrated forms of SC, which are divided into the multilayered model and the vertical value chain model (see Figure 1.8).

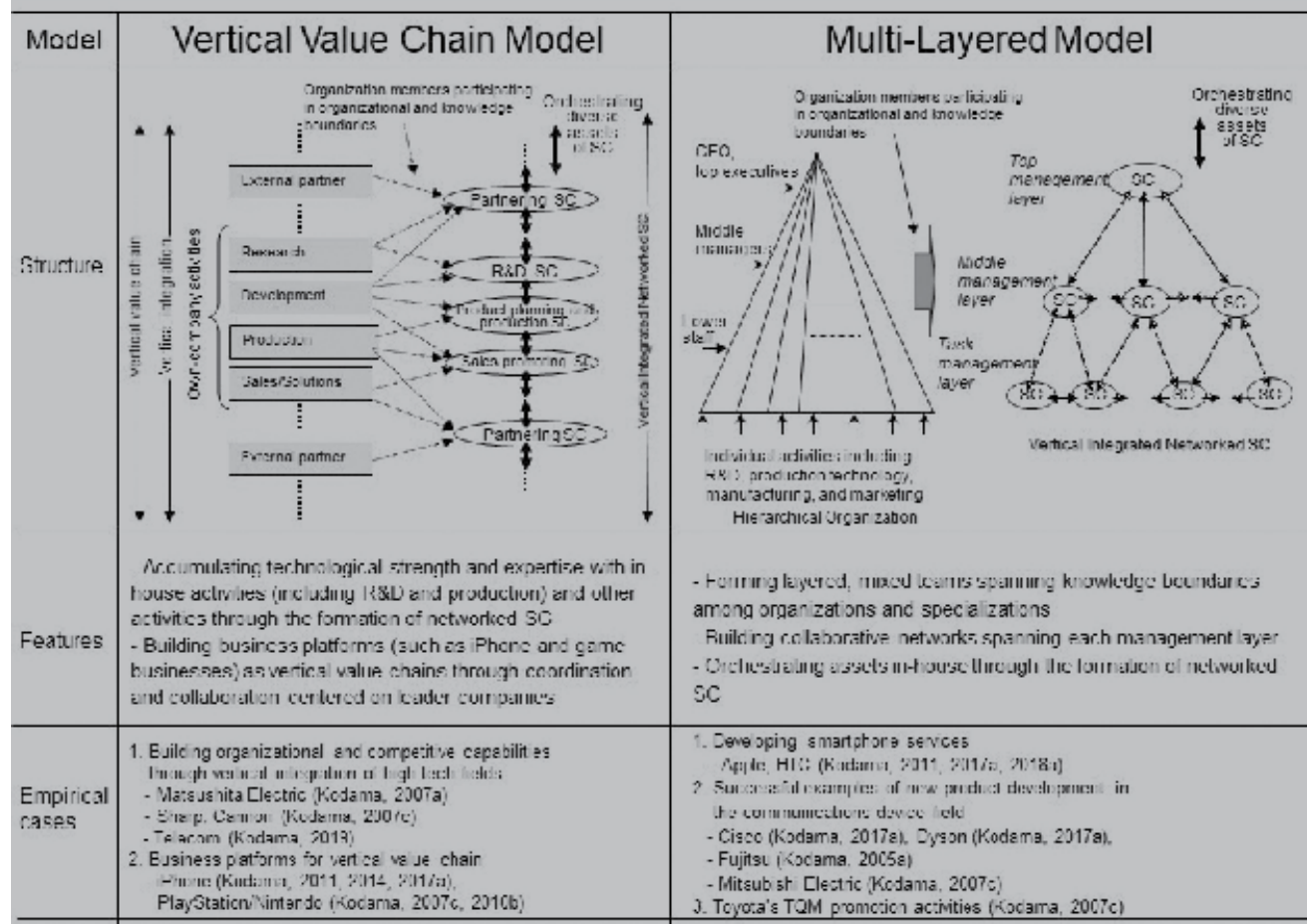

\section{Figure 1.8 Vertical integrated architecture}

(a)

\section{Multi-layered model}

In the multilayered model, SC have hierarchy and are structured through the cross-functional formation of multiple SC by practitioners working in various functional sections of a company at the same time as the formation of hierarchical networks at management levels. The multilayered model is often observed in large-scale cases of new product development (NPD) or large-scale projects (Kodama, 2005a, 2007c, 2009a). For example, in the NPD multilayered model, professionals in various divisions and specialist areas collaborate and form SC at all management levels to design overall architecture for the target developmental product, various subsystems design, software development, hardware development, and production technologies, etc. Moreover, these SC are hierarchical. The reason for this is product architecture is dependent on product functions and product structure (whether its components are integral or modular, or a mix of the two), and because the entire systems 
can be broken down into a hierarchical structure of many subsystems (e.g., Baldwin and Clark, 2000; Clark, 1985; Simon, 1996). Specific empirical cases have been reported for corporations in the IT field (e.g., Kodama, 2005a).

The multilayered model has been observed in product development processes requiring convergence and integration of a wide range of technologies. For example, this was an effective organizational architecture for achieving large-scale business model development or NPD such as Apple's iPod or iPhone (Kodama, 2011, 2017a, 2018a). In this multilayered model, individual and autonomous SC consisting of groups of professionals secure creativity and flexibility when turning missions to achieve new product developments and business models into specific tasks. SC hierarchy has the advantage of securing efficiency and speed of decision-making in executing tasks.

\section{(b)}

\section{Vertical value chain model}

The vertical value chain model means the formation of SC, and networked SC consisting of these as vertical integration for coordination and collaboration among various tasks to achieve vertical integration in all tasks in a company such as $R \& D$, product technologies, manufacturing and sales. Empirical cases of networked SC that achieve in-house vertical integration in Japanese manufacturers have been reported (e.g., Kodama, 2007a, c, d, e, 2017a). As discussed in existing research, networks of SC between different organizations and specialist areas in appliance and communications equipment manufacturers, or telecommunications carriers, orchestrate internal assets and bring about vertical integration-type business models unique to their companies.

Also, these vertical value chain models function to network companies with strong ties in the mobile telephone industry involved in smartphones, etc. and the automotive industry. In networked SC, creating these vertical value chain models in these industries in which the level of knowledge and information sharing is high, leader companies (for example, Apple, Google, GM, Toyota etc.) have bargaining power and leadership in technologies and markets (Kodama, 2011, 2014, 2017a, 2018a). For example, these are typified by the inter-company networks of automotive manufacturers (Toyota, etc.) and components manufacturers (e.g., Amasaka, 2004; Dyer and Hatch, 2004).

Smartphone business models also consist of vertical integration-type value chains of component manufacturers (hardware/software), smartphone manufacturers, application providers (AP) (SNS, etc.) and content providers (CP). In Apple's iPhone development, the mobile phone function details and technical architecture and detailed specifications needed to achieve these functions are decided, and then design and development takes place in-house based on these details (software such as the operating systems, and some hardware parts such as semiconductors). In contrast, electronic manufacturing services (EMS) deliver completed products to Apple. This entails deep sharing of information and knowledge between Apple and the main partner companies brought together through strongly networked SC. Moreover, Apple exercises its authority to control many AP and CP to determine what applications and content from which AP or CP will be included with or adopted for the iPhone. Hence, for Apple, coordinating huge numbers of AP and CP through vertical integration is an important task (Kodama, 2011, 2017a, 2018a). Game businesses such as Sony Computer Entertainment's PlayStation, Nintendo's Wii and Switch also entail coordination of many game software producers, components manufacturers and EMS through vertical 
integration (Kodama, 2011, 2017a).

Behind the success of the smartphone businesses such as Apple (Kodama, 2011, 2017a), not only small-world networked SC between the entrepreneurial organizations and traditional organizations within Apple but also numerous small-world networked SC consisting of parts manufacturers, EMS, AP and CP are formed. Thus, for Apple, the way clusters as small-world networked SC are formed by linking certain external partners is key. The birth of the iPhone business model entailed the formation of numerous small-world networks in-house at Apple and between parts manufacturers, EMS, AP and CP to enable the co-creation of new business models as Apple collaborated with its external partners. Hence, this vertical value chain model accelerated the asset orchestration process by the formation of networks of small-world structures (networked SC) both inside and outside of Apple, and was an important factor in driving the co-evolution of the new business model in the smartphone industry (business ecosystem).

(c)

The vertical integrated architecture and the "creativity view"

The unique creativity view of companies (Kodama, 2009a, b) promotes the building of a vertical integrated architecture. In particular, innovative companies like Apple drive asset orchestration by mobilizing the assets of individuals in various locations through the formation of networked SC to achieve creative technological innovation under a multilayered model. In addition, the level of creativity is raised to respond to new technical changes and develop new technologies by accumulating the intangible assets (tacit knowledge) of know-how and experience between tasks through a vertical value chain model. As well as that, the vertical value chain model enabled through networked SC transcending companies is a factor in the formation of unique business platforms such as creative smartphone businesses (e.g., iPhone, iPad, iCloud, etc.).

\section{Horizontal Integrated Architecture}

Horizontal integrated architecture means horizontally integrated forms of SC, which are divided into the horizontal value chain model and the complementary model (see Figure 1.9). 


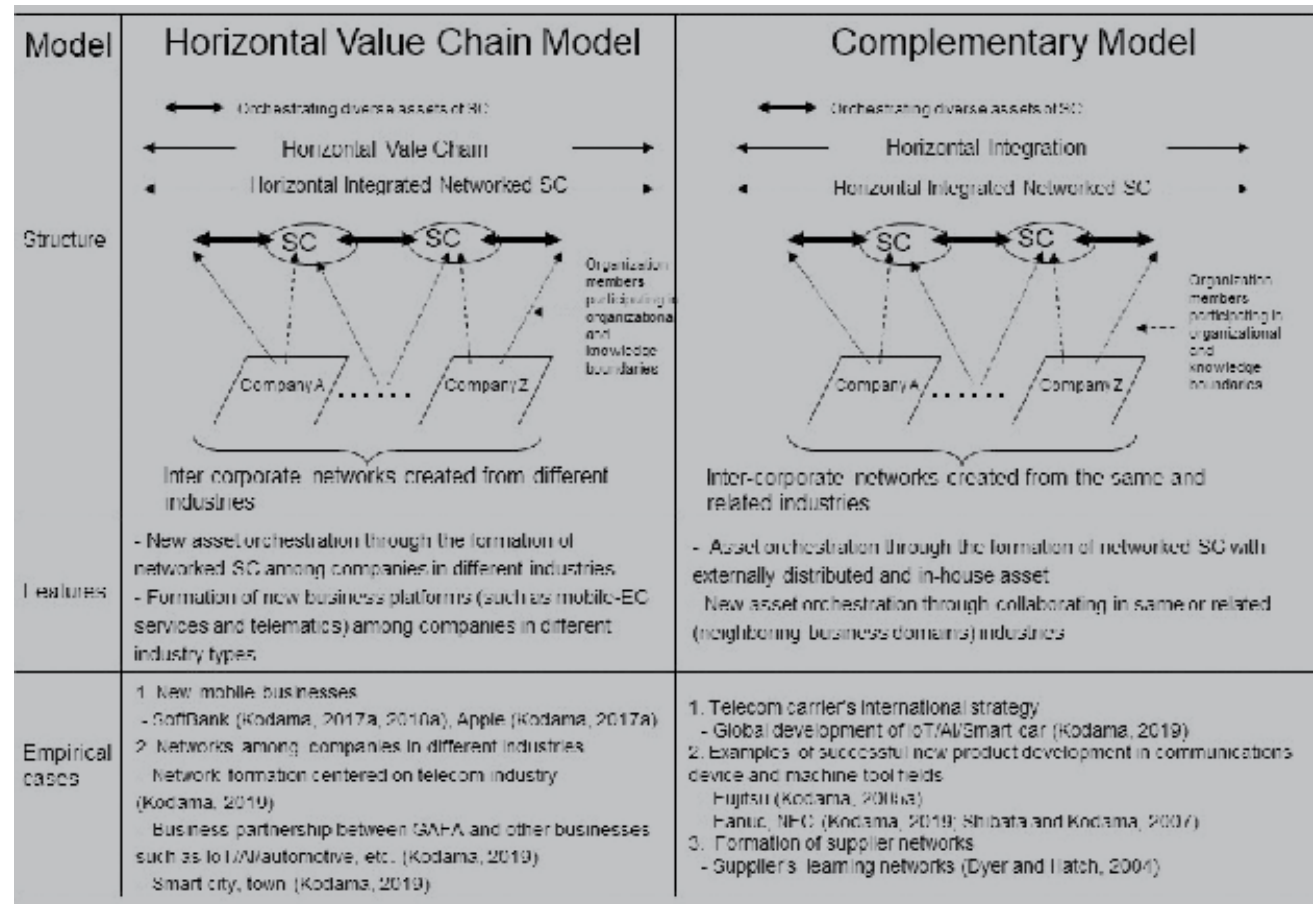

Figure 1.9 Horizontal integrated architecture

\section{(a)}

\section{Horizontal value chain model}

The horizontal value chain model entails the construction of networked SC to expand business to new areas from existing business domains, and build new value chains. In other words, to answer questions such as what kind of products and services a company should keep or what kind of business diversification a company should achieve to bring about value, a horizonal value chain model is a factor that determines the horizontal boundaries of a company. In particular, small-world networks between different industries and businesses drive access to dissimilar assets (knowledge), and drive dialogue on knowledge boundaries. Creative learning (see Figure 1.3) through creative abrasion and productive friction on knowledge boundaries inspires new assets, and raises the creativity needed to achieve new business models. Apple's strategy transformation from its PC business to music distribution and smartphone businesses in recent years is a good example of this (Kodama, 2011, 2017a, 2018a).

As observed in collaborations with multiple players in various industries and the so-called GAFA (Google, Apple, Facebook, Amazon) business leaders in the Internet field, new business models such as electronic money using smartphones, credit card businesses, convergence of communications and broadcasting (merging of Internet businesses with TV broadcasting for mobile phones), convergence of mobile phones and automobiles (Telematics), self driving vehicles, IoT/AI/big data, various sharing services and e-healthcare, are enabled by building horizontal value chains through the formation of networked SC across 
dissimilar types of businesses (Kodama, 2018b, 2019). Such asset orchestration architecture entails proactively forming strategic alliances, or alliances through capital participation and M\&A in the finance, credit card, broadcasting, railroad, distribution, tourism, healthcare, education, advertising and automobile industries to achieve Internet businesses with new added value.

Asset orchestration architecture through the formation of business networks covering different types of business is an important factor in building horizontal value chains to generate new business models.

\section{(b)}

\section{Complementary model}

Complementary models entail collaborative SC and networked SC on an equal footing with external partners in the same industry (or in adjacent business areas), and do not have many of the hierarchical elements seen in vertical integrated architecture. This model entails cases of disseminating common knowledge with external partners, and engaging in joint development of new products and services, etc. on an equal footing. Joint developments with competing or partner companies are also examples of this complementary model. With NPD in the high-tech field, there are many cases of successful NPD through collaboration enabled by the formation of networked SC with numerous external partners. Automotive, appliance, communications equipment and machine tool manufacturers execute horizontal integration of external assets by absorbing the assets of external partners (specialist partners in business layers of horizontal divisions of labor) by the formation of external networked SC with external partners, while orchestrating assets through vertical integration by the formation of networked SC internally. In the case of Fanuc of Japan (e.g., Kodama, 2019), networked SC are fundamental to the asset orchestration architecture to orchestrate external assets with those in-house. Also, as a case in the automotive industry, the learning networks that are continually formed among suppliers to Toyota are also examples of this complementary model.

(c)

\section{Horizontal integrated architecture and the "dialectic view"}

The unique dialectic view of companies (Kodama, 2009a, b) promotes the building of a horizontal integrated architecture. To build win-win relationships in business models, innovative companies drive the orchestration of diverse assets through the formation of networked SC with partners including companies in different industries. Also, the dialectic view drives coordination and collaboration among partners (including competitive companies) through complementary model constructions, and achieves NPD and joint business. In addition, co-creation between dissimilar businesses through the formation of the horizontal value chain model generates new business models and drives co-evolution across entire new industries.

\section{Linkage Relationship Architecture}

Boundaries are asset platforms that entail practitioners sharing dynamic contexts (time, location, relationships with people) to generate new knowledge. "SC as boundaries" are equivalent to space-time that generates and changes through the synergies between individuals sharing and changing contexts with each other - an SC is space-time for sharing 
intangible assets (tacit knowledge), dialogizing and practicing.

"Organizations" and "individuals" are in dialectic relationships with each other, hence the humanity of individual practitioners changes organizations through recursive relationships between organizations and "here and now" space-time as an SC and "practical consciousness" - tacit knowledge in dynamic contexts. While human beings have to accept the limitations of the organizations that they have created, they also have the practical power to transform those organizations (Giddens, 1984; Giddens and Pierson, 1998). SC are platforms that bridge individuals with organizations (companies), and through their micro-existence, human beings form (or eliminate) SC or link them together, and in doing so, have influence on macro structures such as organizations, companies, industries or even entire societies.

Accordingly, SC are important not only as macro-micro linkages in social networks, but also as units for analysis from the perspective that how they influence company performance through the generation and accumulation of social capital (Coleman, 1988; Burt, 1997; Nahapiet and Ghoshal, 1998; Cohen and Prusak, 2000) as individuals form and link $\mathrm{SC}$ in relationships between individuals, organizations, SC, companies and industries, and how they conversely influence individuals.

On the other hand, in the flow of knowledge management, SC are also important to the clarification of processes in which social capital as knowledge capital is born centered on $\mathrm{SC}$, and various knowledge transcending SC boundaries are integrated. Also, there is practical significance for practitioners on the perspective of how new knowledge is born through the formation and linking of SC (see Figure 1.10).

The new perspective obtained from the case of the aforementioned iPhone business model (Kodama, 2011, 2014, 2017b, 2018a) is the fact that diverse, different and multilayered SC whose contexts are always different and networked structures of these exist. These are formed and linked together as practitioners proactively work on others in their environment (customers, etc.) or in their organizations. Practitioners intentionally (or emergently) form and link SC. In particular, as observed in the case of Apple, new product development in the high-tech fields in recent years have led to the necessity to converge and integrate dissimilar technologies. Historically, technological innovation was developed through the pursuit of specialized knowledge in a particular field, but there are now many cases of new products and services that have been developed with new and unconventional ideas that converge technologies from one area with those of another (Kodama, 2014).

An important issue is how to integrate different and dispersed assets. From a technical perspective, this means what kind of technology integration to engage in and co-specialize (e.g., Teece, 2007) with assets in different technological fields. Dispersed assets are embedded in SC dispersed in space-time. To orchestrate assets, individual assets must transcend the boundaries of SC and be networked together. Put differently, distributed SC must be joined in networks, and the knowledge dispersed throughout those SC must be deeply embedded in the networks. In terms of social network theory, SC can be interpreted as cliques of practitioners (collections of actors with close mutual ties), and the network connections between SC and SC are equivalent to ties.

Practitioners committed to multiple SC play a central role in tying together SC with $\mathrm{SC}$ for asset orchestration. For dissimilar knowledge to be integrated, practitioners must deeply understand and share dissimilar assets (tacit knowledge and explicit knowledge) in 
respective $\mathrm{SC}$, and also must deeply embed shared knowledge in networks that transcend the borders of SC (the factor of deep embeddedness is crucial) (Kodama, 2005a, 2005b). In particular, for intangible asset (tacit knowledge) sharing, it is necessary to deeply share contexts on networks, and strongly tie together SC with each other.

In the iPhone value chain, SC are strongly tied together and dissimilar assets are shared through deep embeddedness to generate new knowledge as technical convergence for new products and services. In this way, "building SC networks with strong ties" is an important proposition in integrating dissimilar assets (knowledge), and practitioners must intentionally consider SC relationships as these strong ties.

On the other hand, according to the teachings of social network theory, it is also possible to bridge new dissimilar information with weak ties (Granovetter, 1973). Also, Burt (1992) identified the high possibility of acquiring new business opportunities by actors accessing new information through weak ties with "structural holes". Hence, corporations need to focus on cases where the building of SC networks with weak ties is an effective measure (see Figure 1.9).

Also, while there is not much case research in the field of business, smartphone businesses such as the iPhone could be one of these. The iPhone business model consists of the integration of various assets (knowledge) such as components (hard and soft), smartphone development, technical platform development, manufacturing, applications and contents development. Among these, the smartphone development and technical platform development were produced in various strongly tied SC formed in and out of Apple's organizations.

On the other hand, regarding the development of various applications and contents (a variety including text content, games, location information, music distribution, movie distribution, various SNS services, electronic money services with QR codes, etc., healthcare, welfare and educational services), Apple does not have close network relationships with particular application and contents providers. Instead, the company builds SC networks with weak ties to application and contents providers (AP and $\mathrm{CP}$ ) to access new application and content information, and hence access opportunities for new application and content business.

As described above, in "asset architecture" to achieve asset orchestration, not only are strongly tied SC networks built, but also weakly tied SC networks are an important proposition in the promotion of new business development, and hence practitioners must intentionally consider both these strongly tied and weakly tied SC relationships and their ongoing combination (or proper usage). This is called "linkage relationship architecture" in asset orchestration. Maintaining or building SC networks with strong ties at the same time as SC networks with weak ties and bridging structural holes in a timely manner enables absorption and integration of dissimilar assets. The iPhone business model can be said to be an example of skillfully using the linkage relationship architecture of SC (Figure 1.11). 


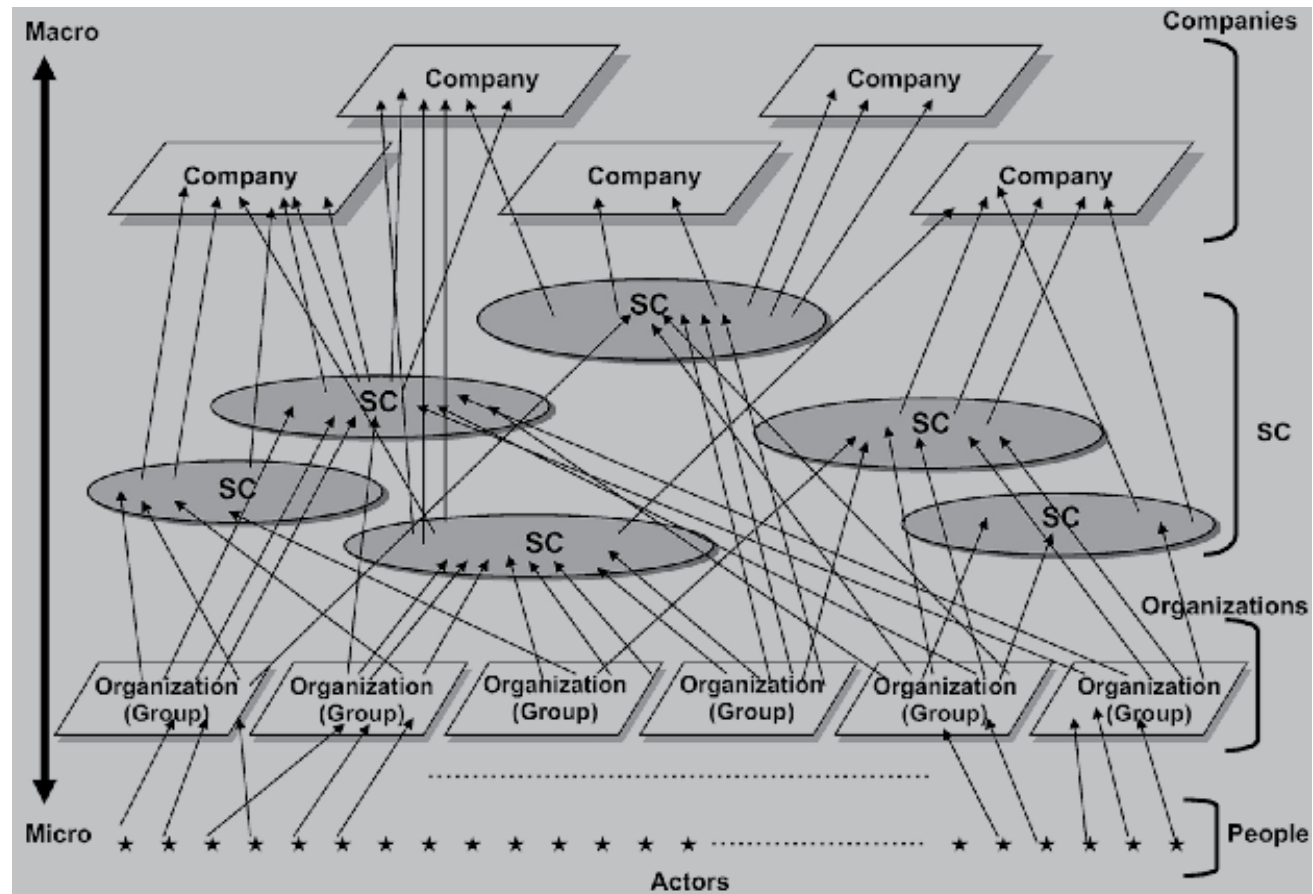

Figure 1.10 Relationship of individuals, organizations and corporations with SC

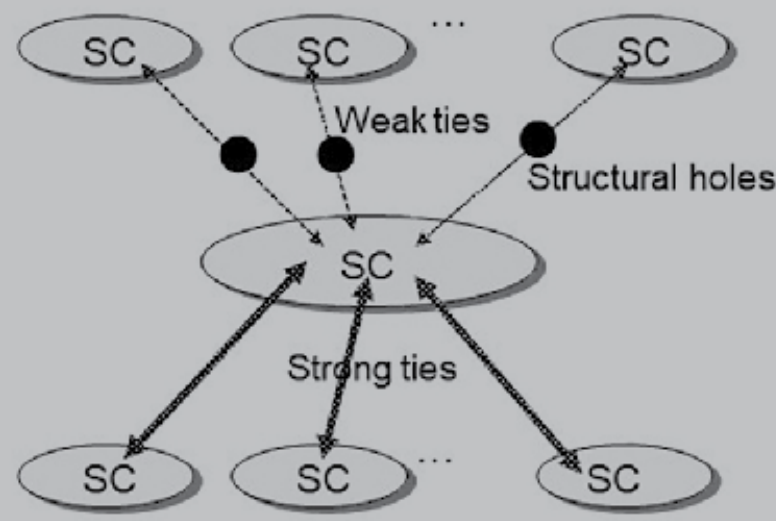

Relationships between SC

Figure 1.11 Linkage relationship architecture 


\subsubsection{Transforming internal and external through asset orchestration dynamics}

(a) Dynamically combining new and existing business

As sensing, boundaries vision is that ability to gain insight to design the most suitable vertical or horizontal boundaries using asset orchestration architecture, architecture thinking as seizing. Not only does that mean dynamically changing the boundaries of a company to suit changing environments (or markets), but also means dynamically changing the company's boundaries to create new environments (markets) and bring out new boundaries innovation (Kodama, 2009a), and is a way of thinking that should not be limited to top management, but acquired by managers at all levels. Asset orchestration dynamics that build and drive the aforementioned boundaries vision and asset orchestration architecture as architecture thinking, and continually and dynamically execute transformation and innovation, are the sub-capability of "transforming" (see Figure 1.3).

The first characteristic of asset orchestration dynamics is its driving ability to dynamically execute the optimization of value chains for a company's core business by changing the vertical boundaries inside and outside of the company. The second characteristic of asset orchestration dynamics is its ability to search out business not only in the periphery of the company's core business but also in different (completely unrelated) business domains, stimulate new business, radically alter the company's horizontal boundaries, uncover the relationships between completely dissimilar knowledge and the company's own knowledge, and demonstrate dissimilar knowledge convergence capability. Asset orchestration dynamics is an enabler that not only promotes growth and development of existing business by refining existing assets, but also creates new business by converging dissimilar assets (knowledge).

The string of innovation research of recent years on radical innovation (e.g., Leifer et al., 2000), breakthrough innovation (e.g., Hargadon, 2003), discontinuous innovation (e.g., Kaplan et al., 2003) and disruptive innovation (Christensen, 1997) has offered both theoretical and practical guidelines of strategy transformation that companies can use to pioneer new markets or create new technologies. The important implication of these innovation strategies is not just to be able to respond quickly to environmental changes, but also to acquire capabilities to drive business development to create new environments (markets). As described by Figure 1.3 , this suggests that changing external environments require a company to execute "environment adaption strategies" to adapt to them, and simultaneously, it is necessary for the company to execute "environment creation strategies" to bring about changes in the environment. These are the core elements of dynamic capabilities.

To swiftly respond to changing circumstances, companies have to continually polish their existing core competencies to fortify their main businesses. Here, incremental innovation by advancing ordinary capabilities (OC) through successive and regular improvement and reform activities is important. In contrast, radical innovation that can acquire new and never-before-seen core competencies through the convergence of differing assets, is needed to acquire the dynamic capabilities (DC) required to drive the development of business for the creation of new environments (markets). Of these two innovation processes - incremental (exploitation) and radical (exploration) - the former pursues the efficiency of existing business (or main businesses) assets (knowledge) in the company, while the latter pursues the creation of assets (knowledge) to pioneer the businesses of the future. However, corporations have to simultaneously manage both of these disparate innovation processes (or properly apply them 
to suit certain situations), and build them into the core of their corporate strategy. This is the crucial function of asset orchestration dynamics.

There is a dynamic relationship between the creation and use of assets (knowledge). Technical know-how and personnel skills are trained through the use of knowledge, thus, in turn, the accumulation of knowledge is the fuel for new asset orchestration. Accordingly, it is important that companies understand how to balance the creation and use of knowledge, and they must be proactive in its management. How can knowledge creativity and efficiency be combined? Put differently, creating knowledge to bring about groundbreaking radical innovation at the same time as using knowledge for incremental innovation of existing core businesses is the proposition of "combined exploration and exploitation" to maintain competitiveness (March, 1991).

For this reason, business leaders and managers need new perspectives to pioneer businesses for new markets, while at the same time accumulating and advancing core assets to reinforce their core businesses. The process of asset orchestration dynamics, which simultaneously executes and combines (or probably applies them to suit the situation) these two substantially different innovation processes to pioneer new and highly individualized strategic positions, is a superior corporate strategy that also leads to the achievement of sustainable competitiveness (e.g., Markides, 1999; see Figure 1.12). Asset orchestration dynamics is a core framework of strategic innovation (Kodama, 2018a) to achieve sustainable corporate growth. Asset orchestration dynamics drive organizational redesign and external shaping, the sub-capabilities of transforming, and entail mutually complementary relationships with these sub-capabilities in Figure 1.3.

The cases of Fujifilm's new business development (Kodama, 2014, 2018a; Kodama and Shibata, 2016), Apple's transformation from its PC business to the music distribution and mobile phone businesses (Kodama, 2011, 2014, 2017b, 2018a), and Japan's 711 and NTT DOCOMO forays into the financial sector (e.g., Kodama, 2007a), are examples of companies that massively altered their horizontal boundaries through asset orchestration dynamics. These companies do not only maintain growth of their existing businesses, but also engage in strategic change for new business. Japanese general trading companies such as Mitsubishi and Mitsui also skillfully combine growth of their existing businesses with R\&D through asset orchestration dynamics (see Box 1.4).

Traditional innovation in mature industries mainly involves companies carrying out research in closed, hierarchical and autonomous systems within themselves in which all processes are controlled by the company, and most or all intellectual properties are held by the company. In closed innovation systems like these, the governance mechanisms bring about the company's unique core competences, and are the source of the company's competitiveness. However, based on transactional cost theory, companies were able to raise business efficiency across the board by changing the vertical boundaries that determine their corporate value chains through outsourcing to other companies for resources and knowledge that they did not have. When circumstantial and environmental change is soft, it is advantageous for a company to configure value chains with vertical integration within the company or group of companies through coordination between related business units and close interdependency of technical resources. The traditional automobile industry, etc. are good examples of this. However, while it may be a strength of path dependency with close internal integration, if the environment changes and a serious problem arises, weaknesses can surface in such close interdependencies 


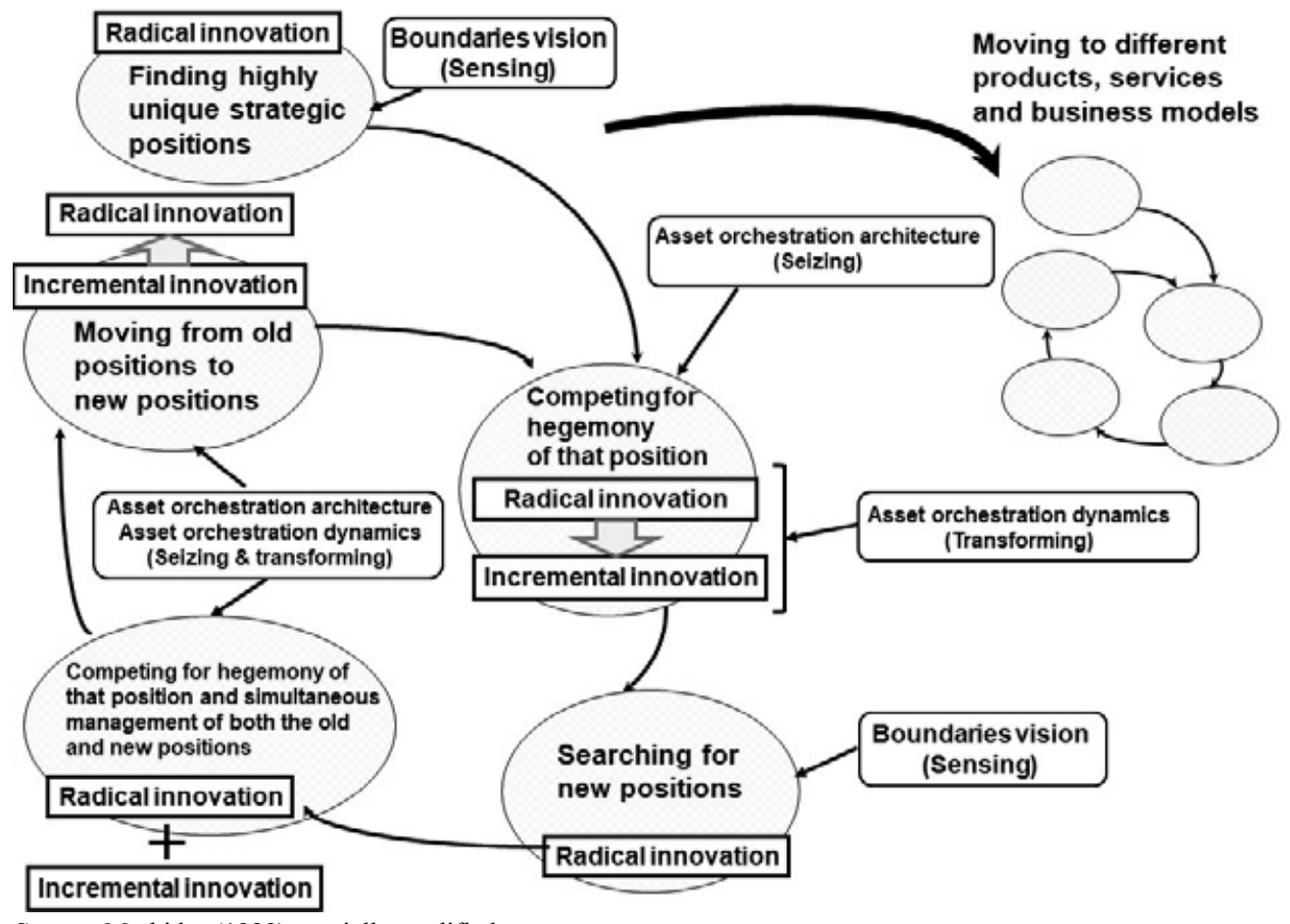

Source: Markides (1999), partially modified.

Figure 1.12 Dynamically combining new and existing business through asset orchestration dynamics

(e.g., Henderson and Clark, 1990; Hargadon and Sutton, 1997; Siggelkow, 2001). Also, fixed technologies or value chains that are a company's strengths can be weakened by changes in the market or destructive technologies (Christensen, 1997; e.g., Levitt and March, 1988; Leonard-Barton 1992, 1995; Martines and Kambil, 1999).

Nevertheless, it will be necessary to dynamically change the corporate boundaries of a company (vertical and horizontal boundaries) while maintaining existing business to shift to the completely different businesses of the future such as environmental vehicle and self driving vehicle developments with AI technologies at their core, and mobility as a service (MaaS). In rapidly changing market circumstances and in the technological environment of convergence, dynamic capabilities as dynamic asset orchestration are required to further strengthen and maintain existing core competencies with selection and concentration, while at the same time proactively bring in knowledge and resources from outside the company and flexibly reassemble accumulated knowledge and resources to respond to the changing circumstances (Teece et al., 1997; Teece, 2007, 2014). This means the processes of boundaries innovation (Kodama, 2009a, 2014) to create new products, services and business models by improving and developing the company's own knowledge, dynamically taking up knowledge 
from outside the company through the processes of open innovation (Chesbrough, 2003) or hybrid innovation (Kodama, 2011), and through the convergence of knowledge within and outside the company.

For this to happen, companies need to engage in the dynamic processes of converging knowledge dispersed within and outside the company and reconfiguring it as necessary. This means that companies have to constantly reconfigure the vertical or horizontal boundaries of the company's business models to respond to circumstantial change (or intentionally create new circumstantial change as convergence). As in the Fujifilm case, horizontal boundaries are a driver that determines the strategic domain for businesses related to a company's core business or new business (Kodama, 2018a).

To achieve new business models, it is important to dynamically integrate internal assets (knowledge) by integrating internal corporate boundaries (between people, organizations and different areas of technical specialty) through internal convergence networks with external assets (knowledge), and integrating external corporate boundaries (between companies, between companies and customers, and between different industries, etc.) through external convergence networks using the practice of asset orchestration dynamics. Through the asset convergence process entailing asset orchestration dynamics via convergence networks both within and outside companies on these vertical and horizontal boundaries, new assets (knowledge) transcending diverse boundaries are created. In this book, companies that achieve boundaries innovation through asset orchestration dynamics in this way are referred to as "asset orchestration firms" (see Figure 1.13).

\section{Asset Orchestration Firm}

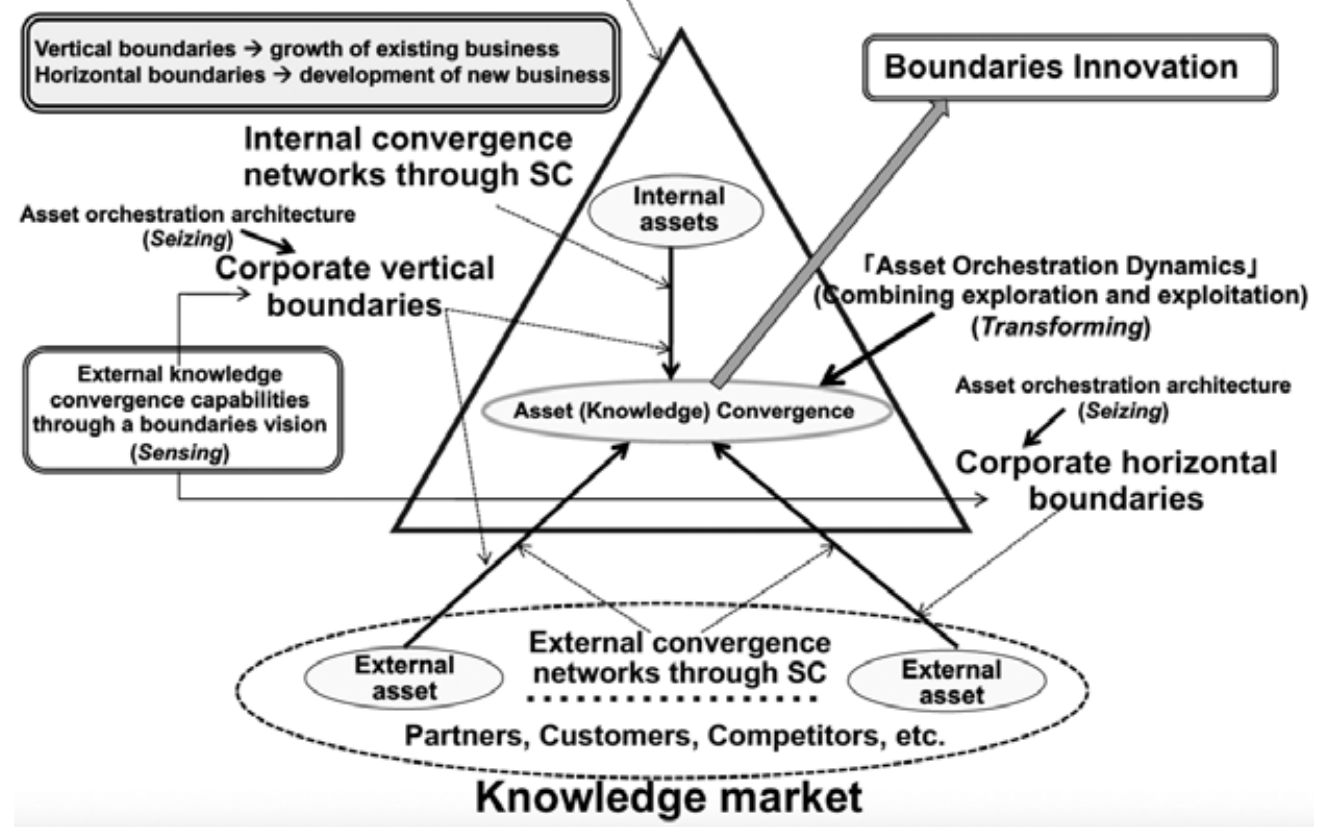

Figure 1.13 Asset orchestration firm 
In order to not only grow their core businesses but also to acquire new business opportunities, asset orchestration firms use their dissimilar knowledge integration capabilities through boundaries vision (sensing) of vertical or horizontal boundaries. They cleverly combine assets inside the company, in group companies, in the same industries, in different industries and in customers through strategic alliances, strategic outsourcing, joint developments, ventures and M\&A etc., and demonstrate capabilities (asset orchestration dynamics) (transforming) to keenly and prudently acquire new assets by building and establishing asset orchestration architecture (seizing). These asset orchestration dynamics activities are factors in the formation of healthy business ecosystems with all stakeholders such as the company and its partner group companies.

For example, fabless companies like Apple, Nintendo and Qualcomm use selection and concentration to clearly define their vertical boundaries, concentrate resources on R\&D and product planning, and build ecosystems to provide end-users with final products through collaboration strategies with leading global partners (components manufacturers, manufacturers, distributors and sales enterprises, etc.; e.g., Kodama, 2011). Also, telecommunications carriers such as the Japanese company SoftBank and Taiwan's Chunghwa Telecom concentrate resources on product planning as well as telecommunications infrastructure and facilities businesses, while engaging in collaboration strategies with their best global partners (mobile telephone device manufacturers, communications equipment manufacturers, software vendors, semiconductor manufacturers, contents providers application vendors and other corporations) to build and advance their smartphone business value chains and ecosystems (e.g., Kodama, 2009b, 2011).

Boundaries innovation is generally divided into incremental innovation for changing a company's core business and radical/breakthrough innovation for bringing about new business. As described earlier, the formation of internal convergence networks (internal asset convergence) and external convergence networks (external asset convergence) through building asset orchestration architecture (seizing) is crucial in processes for achieving these two types of innovation.

To achieve incremental innovation, value chains must be optimized through the formation of internal convergence networks and external convergence networks to respond to changing environments (or markets). On the other hand, to achieve radical innovation, it is necessary to configure new value chains for the creation of new environments (or markets). For this reason, the boundaries where dissimilar assets (knowledge) intersect must be uncovered, external convergence networks built, and these many assets (knowledge) converged. Companies dynamically form these internal convergence networks and external convergence networks through external knowledge convergence capabilities using boundaries vision and the building of asset orchestration architecture (seizing). Thus, through the practice of asset architecture dynamics (transforming), companies dynamically change their horizontal and vertical boundaries to combine exploration and exploitation (see Figure 1.13).

It is the aforementioned SC that form the basis of these network configurations. This means that from the micro perspective, networks are made up of people or knowledge, whereas from the macro perspective, networks can be seen as collections of linked groups, organizations and companies (e.g., Kodama, 2005b). These can span different job functions and diverse layers of management, and exist both within and outside companies, and include customers. To date, the relationship between networks of companies and innovation has been reported in 
much academic research (e.g., Powell and Brantley, 1992; Powell et al., 1996; Rosenkopf and Tushman, 1998). In the concept of driving boundaries innovation in this way, SC as networks (and networked SC) dynamically formed by practitioners tie together multi-layered dissimilar $\mathrm{SC}$ assets (knowledge) to build ecosystems within and between companies and across industries, and raise the potential to bring about boundaries innovation.

Building strategic communities brings about organizational transformation and speeds up corporate transforming

According to our research to date, to demonstrate DC and create new markets or new value in dynamically changing markets, practitioners have to demonstrate: (a) context architect capabilities, (b) boundaries consolidation capabilities, and (c) strategy architect capabilities (Kodama, 2011, 2014, 2018a).

"Context architect capabilities" are also the capabilities of innovators to generate new meaning between different contexts. Differences arise on the boundaries between different contexts (Carlile, 2002, 2004). These differences give rise to further diversity and contradictions in various contexts, and are factors that drive boundaries vision. Overcoming contradictions originating in contextual diversity dynamically gives rise to new contexts, which enables sharing of "specific contexts" (Kodama, 2006). To overcome these contradictions, the execution of creative learning through dialectical and creative dialogue (Kodama, 2007b), creative confrontations or abrasion (Leonard-Barton, 1995), productive friction (Hagel and Brown, 2005) and political negotiating practice (Brown and Duguid, 2001) and so forth among practitioners is an important factor.

To achieve their business visions or missions, the context architect capabilities of practitioners to bring about specific contexts enables the creation and practice of new concepts though productive and creative dialogue and learning on questions such as why, how things should be and how to achieve certain things. As a result, the quality of these specific contexts in turn determines the quality of the knowledge produced. In the Apple case mentioned earlier, creating new markets is the vision for the future in which collaborating partners as professionals with a range of backgrounds and skills question themselves and each other to dynamically bring about and share specific contexts.

Next, regarding boundaries consolidation capabilities, the aforementioned specific contexts are rooted in specific practitioners building and rebuilding SC (Kodama, 2005a). Practitioners does not mean simply anybody, but importantly means a number of certain people (Kodama, 2006) who have the human capability of constantly pursuing self improvement. Expressed in the contexts of engineers, this also means specific practitioners who have common knowledge (shared language and knowledge; see, for example, Star, 1989). These people proactively bring about specific contexts based on their beliefs and thoughts, and build and rebuild strategic communities. "Specific practitioners" means executives and managers in managerial layers in organizations, executives and managers in partner companies, and leading customers.

Thus, specific practitioners build "specific strategic communities" to generate valuable new knowledge with the human network systems that they have. The author calls this behavior, and the capability of specific practitioners to link specific organizational and knowledge boundaries together and network them, "boundaries consolidation capabilities". Furthermore, these specific strategic communities are reconfigured over time by practitioners in response 
to strategic objectives. Accordingly, these can more precisely be called "specific strategic communities that change".

Finally, "strategy architect capabilities" are practitioners' capabilities to formulate and implement strategy by dynamically forming strategic communities to bring about new business models through context architect capabilities and boundaries consolidation capabilities. These capabilities include the know-how and skills to draw a grand design of strategy as asset orchestration architecture (seizing) and bring it to reality. A factor of strategy architect capabilities is the practice of asset orchestration dynamics (transforming) to skillfully use and integrate different strategy-making processes to combine exploration and exploitation (see Box 1.4).

The above three capabilities lead to the promotion of the three processes of sensing (boundaries vision), seizing (asset orchestration architecture) and transforming (asset orchestration dynamics) (see Figure 1.3). Because the nine sub-capabilities shown in Figure 1.3 are interconnected in a system, with interactions or synergies in response to environmental changes, the weight of each sub-capability element is a contingent in responses to situations.

Also, the dynamic capabilities framework shown in Figure 1.3 focuses on the situation-adaptive nature of capabilities for handling external change (adaptive or active). There are also critical contingencies in relation to strategy, organizational design and culture within corporations (Day and Schoemaker, 2016). In response to these situations-adaptive changes, subsystem elements (sub-capabilities) within corporate systems must be specified and their characteristics must be scrutinized. This is because the inherently hardened nature of a company's ordinary capabilities (OC) due to the strength of dependency of a corporation's development path, or bureaucracy and dullness of decision-making capabilities caused by organizational inertia limit the speed and scale of change of a company's dynamic capabilities (DC). To avoid this, the "capabilities congruence (dynamic internal congruence)" between the capabilities in a corporate system mentioned at the beginning (congruence between subsystems) [Insight-2] is required. This is discussed in detail in Chapter 9.

\section{BOX 1.4 STRATEGY-MAKING PROCESSES THROUGH DYNAMIC FORMATION OF STRATEGIC COMMUNITIES}

To innovate in uncertain environments, practitioners continuously create concepts for new business models (new products, services and business frameworks, etc.) based on imagination and creativity, and execute emergent strategies (Mintzberg and Walters, 1985) through the formation of multiple emergent external strategic communities (ESC) with strategic partners outside the company, including customers. Emergent strategies are strategies created by practitioners through the process of trial and error at the workplace level (there may be various cases, for example, at the divisions close to customers or middle management) as they recognize changes in the environment that they did not predict. However, in reality, strategy-making processes in corporations are generally intended or deliberate, whereas the details of strategy are emergent. Through the author's long practical experience, it was found that strategy-making processes in corporations have characteristics that are simultaneously planned and emergent (for example, entrepreneurial strategies; Mintzberg, 1978; Kodama, 2007a). 
The two types of organizational forms (emergent organizations that promote exploration for new business, and traditional organizations that drive exploitation for existing business) in "strategic community-based firms" discussed in Kodama (2007a) are broadly defined as emergent organizations pursuing creativity and autonomy, and traditional organizations pursuing efficiency and control. Therefore, they are paradoxical. Thus, there is always a tug of war and conflict occurring between these organizations, and this hinders the integration of the knowledge of formal organizations, internal strategic communities (ISC) within companies and external strategic communities (ESC) outside companies. Nevertheless, "leadership teams" promote this synthesis and achieve transformation of corporate culture (Kodama, 2005b).

These leadership teams are formed from leaders (the CEO, executives, division managers, department managers, project leaders and managers, etc.) at all management levels (top management layer, middle management layer, management teams consisting of top and middle management layers, cross-functional teams, and task forces). As SC and networked SC, leadership teams bring about dynamic (DC) and ordinary (OC) capabilities across entire corporations through the integration and synthesis of knowledge in the two types of formal organizations (emergent and traditional organizations) and/or internal and external strategic communities.

To achieve a strategic community-based firm it is important that leadership teams simultaneously combine the apparently contradictory creative and planned strategic processes (exploration and exploitation) and synthesize them (asset orchestration dynamics (transforming)). Leadership teams at Apple are characterized by their combination of both creativity and efficiency (Kodama, 2017a). Existing research identifies the importance placed on building "ambidextrous organizations" in innovative American corporations by combining organizations driving new business (equivalent to emerging organizations) and organizations driving existing business (equivalent to traditional organizations). However, through our research (e.g., Kodama, 2019), we found it necessary to build leadership teams that have multilayered and "invisible" SC structures for asset orchestration dynamics (transforming) to succeed.

Managers in leader teams engage in deep dialogue and discussion to select strategies and plans that will genuinely enable innovation to flourish, which are then executed through the leadership of those managers. The synergy of leadership enabled by collaboration among managers at all management levels including the CEO and executives focuses creative learning through dialectical dialogue, and promotes carefully selected deliberate strategies to achieve synthesis of the knowledge and strategies of different organizations. At the root of asset orchestration dynamics (transforming) centered on leadership teams lies strategic dynamics of knowledge through abduction to build asset orchestration architecture (seizing) (e.g., Kodama, 2007a). Strategy architect capabilities are also capabilities to execute the abduction process of strategy formulation and implementation through the building and rebuilding of internal and external strategic communities (ISC and ESC). This is the strategy view in the "strategic community-based firm". 


\section{BOX 1.5 JAPANESE GENERAL TRADING COMPANIES' ASSET ORCHESTRATION DYNAMICS (SEE FIGURE 1.14)}

The asset orchestration of Japanese general trading companies is deeply related to formation of their value chains. General trading companies use their multiple functions upstream and downstream in the value chain (finance, investment, consulting, distribution, etc.), and make efforts to optimize their vertical value chain models (see Box 1.3) through collaboration with both internal and external leading partners, and at the same time drive the co-evolution model to build win-win relationships with partners.

The architecture on which value chains are built are the diverse strategic communities spread widely around the world. Thus, the source of the configuring of these strategic communities are the people and human resource networks that can sense, converge, integrate and use diverse, global-scale assets through DC functions (sensing, seizing, transforming). In short, the dynamic configuring of SC and networked SC is an important factor for general trading companies. The specializations required for innovation in general trading companies are indicated by the 3-axis matrix of "the axis of goods and industry, the axis of region and the axis of function" and "people $\times$ goods $\times$ services $\times$ know-how as information", and entrepreneurial persons ideally having goods, region and function orchestrate assets on the global scale.

New business development in general trading companies are R\&D-type business commercialization processes, and differ from the closed innovation of traditional manufacturers, in that asset orchestration through the convergence and integration of multiple assets via open innovation (Chesbrough, 2003) with leading internal and external partners is dominant.

With vertical integrated architecture as asset orchestration architecture (see Box 1.3), how should the vertical value chain model and the co-evolution model committed from the upstream, midstream through to the downstream be configured? In industries structured with the horizontal specialization business model such as the IT industry, how should a company collaborate with other companies to concentrate business resources into the certain functions of value chains, and configure the overall target value chain (vertical value chain model and co-evolution model)? Or should resources be concentrated into certain specialist areas only with horizontal integrated architecture or linkage relationship architecture to maximize profits? Or, how should new value chains be configured by converging and integrating the strength of a company with that of another by finding partnerships (with strong or weak ties) with other companies to compensate for the weaknesses of a company or through strategic collaboration across different business types, etc.? In any case, when general trading companies pioneer new businesses, considering how to uncover business models and value chains is required in these $R \& D$ processes.

Accordingly, based on open innovation thinking, managers of general trading companies allow expanded diversity of asset orchestration architecture (vertical integrated architecture, horizontal integrated architecture, leadership relationship architecture: see Box 1.3), and concentrate on the core businesses selection process through experiments and trials to build optimized value chains (the vertical value chain model and co-evolution model). Furthermore, they pursue the process of hypothesis verification and selection to suit strategic objectives with their diverse "asset architectural thinking". 
In contrast, "value chain development-type" businesses entail developmental review of vertical integrated architecture and, depending on the situation, horizontal integrated architecture and linkage relationship architecture to uncover new partners or rethink partnerships in the horizontal direction to build new vertical value chain models. Thus, asset orchestration in this domain entails developmental review of strategic objectives.

In "domain horizontal expansion-type business", as an applied asset model, existing vertical integrated architecture is adopted, strategic objectives remain almost unchanged, and partners are selected by geographical considerations. Or, successful models are applied and adopted by adjacent areas, horizontal boundaries are extended, and existing vertical value chain models are adapted and applied to horizontal boundaries. On the other hand, in the shift from R\&D-type business to commercialization, strategy objectives and plans are determined and concentrated, and the asset orchestration architecture selected as a result of hypothesis testing is further optimized in its entirety.

In existing businesses, continual maintenance of strategic planning is crucial. Hence, asset orchestration architecture is pursued for efficiency to strengthen and maintain the value chains of such existing businesses. As discussed above, general trading companies execute asset orchestration dynamics by flexibly selecting and properly using the company's asset orchestration architecture and configuring vertical value chain models and co-evolution models, to dynamically combine the growth and development of existing business and the pioneering of new businesses (and properly apply these to suit the situation), by using their capabilities to achieve their strategies in the target business domains and value chains.

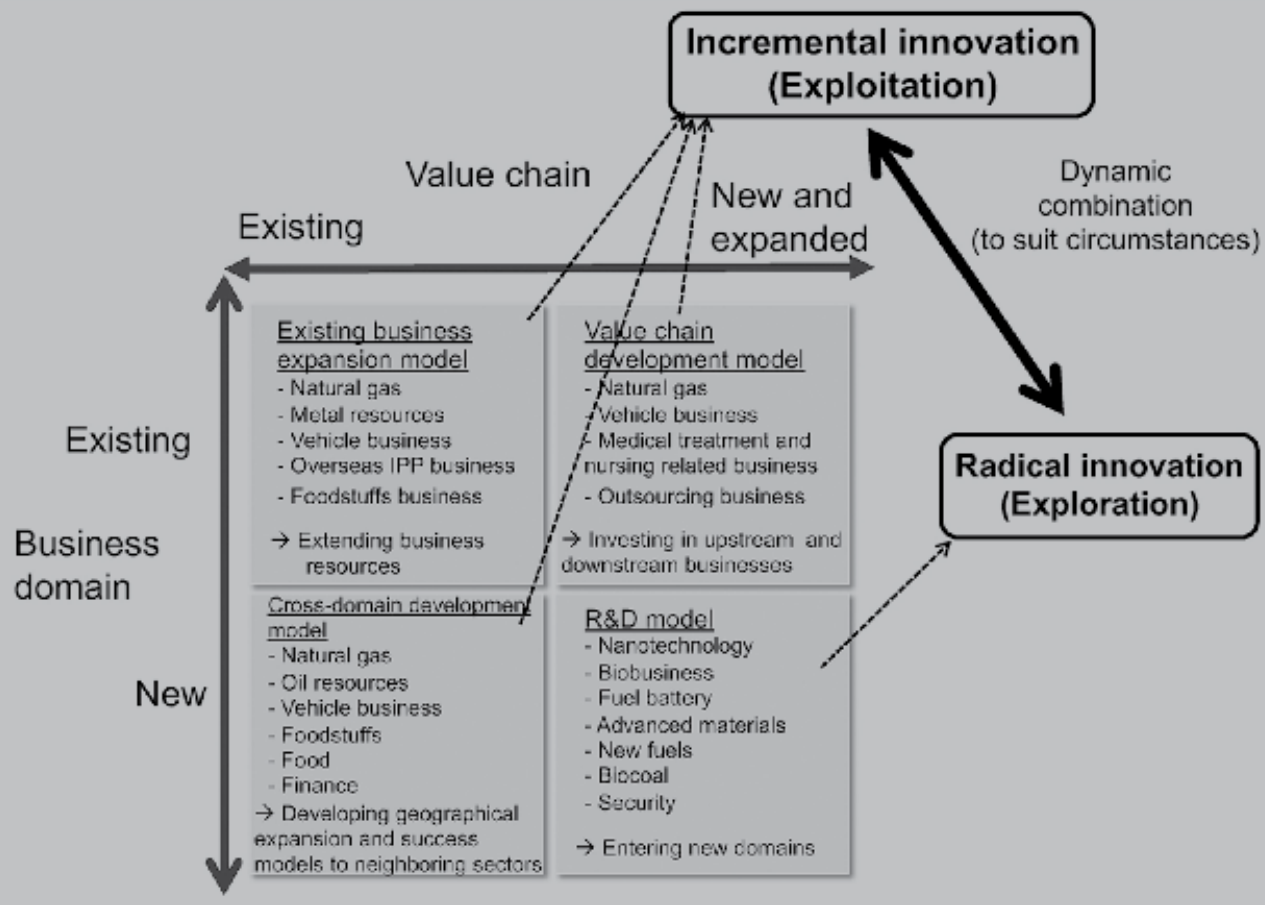

Figure 1.14 Japanese general trading companies' asset orchestration dynamics 


\section{CONCLUSION OF THIS CHAPTER}

This chapter has presented the new concept of "boundaries vision", and new perspectives from a theoretical, empirical and practical viewpoint on the relationship between boundaries vision and "sensing" in "dynamic capabilities" (e.g., Teece, 2007, 2014), the core framework of strategic management. Then, the chapter proposed that "sensing through boundaries vision" raises the creativity of practitioners, organizations and corporations. Moreover, the chapter has presented how the three DC framework sub-capabilities of sensing (boundaries vision), seizing (asset orchestration architecture) and transforming (asset orchestration dynamics) achieve dynamic combination of exploration and exploitation through the dynamic reconfiguration of corporate and organizational boundaries, and hence promote boundaries innovation.

\section{NOTE}

1. The Apple-centered "Small-World Network" (SW) consists of hubs and a network structure resembling a scale-free network (Barabasi, 2002) with a huge number of links. Barabasi (2002) also observes a similar trend, in which 80 percent of all World Wide Web connections are "occupied" by only 20 percent of "hub" websites. Realistically, however, the number of business-related partners is limited. At the same time, a company comprised of micro-practitioners who think subjectively must discuss the pros and cons as well as transaction costs of building relationships with partners. This is why the networked SC formation differs somewhat (Watts, 2003) from the highly centralized, scale-free network (Cole and Cole, 1973; Barabasi and Albert, 1999).

\section{REFERENCES}

Abernathy, W.J. and Utterback, J.M. (1978), 'Patterns of industrial innovation', Technology Review, 80(7), 40-47.

Amabile, T.M. (1979), 'Effects of external evaluation on artistic creativity', Journal of Personality and Social Psychology, 37(2), 221-233.

Amabile, T.M. (1982), 'Social psychology of creativity: A consensual assessment technique', Journal of Personality and Social Psychology, 43(5), 997-1013.

Amabile, T.M. (1983), 'Brilliant but cruel: Perceptions of negative evaluators', Journal of Experimental Social Psychology, 19(2), 146-156.

Amabile, T.M. (1985), 'Motivation and creativity: Effects of motivational orientation on creative writers', Journal of Personality and Social Psychology, 48(2), 393-399.

Amabile, T.M. (1988), 'A model of creativity and innovation in organizations', Research in Organizational Behavior, 10(1), 123-167.

Amabile, T.M. (1995), 'Attributions of creativity: What are the consequences?', Creativity Research Journal, 8(4), 423-426.

Amabile, T.M. (1996), Creativity in Context: Update to the Social Psychology of Creativity, Boulder, CO: Westview Press.

Amasaka, K. (2004), 'Applying new JIT-A management technology strategy model at Toyota: strategic QCD studies with affiliated and non-affiliated suppliers', Proceedings of the Production and Operations Management Society, Cancun, Mexico, 1-11.

Argyris, C. (2004), 'Double-loop learning and implementable validity', in Tsoukas, H. and Mylonopoulos, N. (eds), Organizations as Knowledge Systems, London: Palgrave Macmillan, pp. 29-45.

Argyris, C. and Schon, D. (2004), Theory in Practice: Increasing Professional Effectiveness, San Francisco: Jossey Bass.

Baldwin, C.Y. and Clark, K.B. (2000), Design Rules, Vol. 1: The Power of Modularity, Cambridge, MA: MIT Press.

Barabasi, A.-L. (2002), Linked: The New Science of Networks, Boston: Perseus. 
Barabasi, A.-L. and Albert, R. (1999), 'Emergence of scaling in random networks', Science, 286, October, 509-512.

Brown, J.S. and Duguid, P. (2001), 'Knowledge and organization: A social-practice perspective', Organization Science, 12(6), 198-213.

Burt, R. (1992), Structural Holes: The Social Structure of Competition, Cambridge, MA and London: Harvard University Press.

Burt, R. (1997), 'The contingent value of social capital', Administrative Science Quarterly, 42(2), 339-365.

Carlile, P. (2002), 'A pragmatic view of knowledge and boundaries: Boundary objects in new product development', Organization Science, 13(4), 442-455.

Carlile, P. (2004), 'Transferring, translating, and transforming: An integrative framework for managing knowledge across boundaries', Organization Science, 15(5), 555-568.

Chesbrough, H. (2003), Open Innovation, Boston, MA: Harvard Business School Press.

Christensen, C.M. (1997), The Innovator's Dilemma: When New Technologies Cause Great Firms to Fail, Boston, MA: Harvard Business School Press.

Clark, K.B. (1985), 'The interaction of design hierarchies and market concepts in technological evolution', Research Policy, 14(2), 235-251.

Clark, K.B. and Fujimoto, T. (1991), Product Development Performance: Strategy, Organization, and Management in the World Auto Industry, Boston, MA: Harvard Business School Press.

Cohen, D. and Prusak, L. (2000), In Good Company: How Social Capital Makes Organizations Work, Boston, MA: Harvard Business School Press.

Cole, R. and Cole, S. (1973), Social Stratification in Science, Chicago: University of Chicago Press.

Coleman, J. (1988), 'Social capital in the creation of human capital', American Journal of Sociology, 94, 95-120.

Cyert, R.M. and March, J.G. (1963), A Behavioral Theory of the Firm, Englewood Cliffs, NJ: Prentice Hall.

Day, G.S. and Schoemaker, P. (2004), 'Peripheral vision: Sensing and acting on weak signals', Long Range Planning, 2(37), 117-121.

Day, G. and Schoemaker, P.J. (2005), 'Scanning the periphery', Harvard Business Review, 83(11), $135-148$.

Day, G.S. and Schoemaker, P.J. (2016), 'Adapting to fast-changing markets and technologies', California Management Review, 58(4), 59-77.

Dyer, J.H. and Hatch, N.W. (2004), 'Using supplier networks to learn faster', MIT Sloan Management Review, 45(3), 57-63.

Elsbach, K.D. and Hargadon, A.B. (2006), 'Enhancing creativity through "mindless" work: A framework of workday design', Organization Science, 17(4), 470-483.

Ericsson, K.A. and Lehmann, A.C. (1996), 'Expert and exceptional performance: Evidence of maximal adaptation to task constraints', Annual Review of Psychology, 47(1), 273-305.

Fauconnier, G. and Turner, M. (1998), 'Conceptual integration networks', Cognitive Science, 22(2), 133-187.

George, J.M. and Zhou, J. (2007), 'Dual tuning in a supportive context: Joint contributions of positive mood, negative mood, and supervisory behaviors to employee creativity', Academy of Management Journal, 50(3), 605-622.

Giddens, A. (1984), The Constitution of Society, Berkeley, CA: University of California Press.

Giddens, A. and Pierson, C. (1998), Conversation with Anthony Giddens: Making Sense of Modernity, Oxford: Blackwell Publishers Ltd.

Granovetter, M. (1973), 'The strength of weak ties', American Journal of Sociology, 78(6), 1360-1380.

Hacklin, F., Marxt, C. and Fahrni, F. (2009), 'Coevolutionary cycles of convergence: An extrapolation from the ICT industry', Technological Forecasting and Social Change, 76(6), 723-736.

Hagel III, J. and Brown, J.S. (2005), 'Productive friction', Harvard Business Review, 83(2), 139-145.

Hargadon, A. (2003), How Breakthroughs Happen: The Surprising Truth about How Companies Innovate, Boston, MA: Harvard Business School Press.

Hargadon, A. and Sutton, R. (1997), 'Technology brokering and innovation in a product development firm', Administration Science Quarterly, 42, 716-749. 
Helfat, C. and Martin, J. (2015), 'Dynamic managerial capabilities: A perspective on the relationship between managers, creativity and innovation', in Shalley, C.E., Hitt, M.A. and Zhou, J. (eds), The Oxford Handbook of Creativity, Innovation and Entrepreneurship, Oxford: Oxford University Press, pp. 421-433.

Helfat, C.E. and Peteraf, M.A. (2015), 'Managerial cognitive capabilities and the microfoundations of dynamic capabilities', Strategic Management Journal, 36(6), 831-850.

Helfat, C.E., Finkelstein, S., Mitchell, W., Peteraf, M.A., Singh, H., Teece, D. J. and Winter, S.G. (2007), Dynamic Capabilities: Understanding Strategic Change in Organizations, Oxford: Blackwell.

Henderson, R.M. and Clark, K.B. (1990), 'Architectural innovation: The reconfiguration of existing product technologies and the failure of established firms', Administrative Science Quarterly, 35(1), 9-30.

Hodgkinson, G.P. and Healey, M.P. (2011), 'Psychological foundations of dynamic capabilities: Reflexion and reflection in strategic management', Strategic Management Journal, 32(13), 1500-1516. Johansson, F. (2004), The Medici Effect, Boston, MA: Harvard Business School Press.

Kaplan, S., Murray, F. and Henderson, R. (2003), 'Discontinuities and senior management: Assessing the role of recognition in pharmaceutical firm response to biotechnology', Industrial and Corporate Change, 12(4), 203-233.

Klein, J.T. (1990), Interdisciplinarity: History, Theory, and Practice, Detroit, MI: Wayne State University Press.

Kodama, M. (2002), 'Transforming an old economy company through strategic communities', Long Range Planning, 35(4), 349-365.

Kodama, M. (2005a), 'Knowledge creation through networked strategic communities: Case studies on new product development in Japanese companies', Long Range Planning, 38(1), 27-49.

Kodama, M. (2005b), 'How two Japanese high-tech companies achieved rapid innovation via strategic community networks', Strategy \& Leadership, 33(6), 39-47.

Kodama, M. (2006), 'Knowledge-based view of corporate strategy', Technovation, 26(12), 1390-1406.

Kodama, M. (2007a), The Strategic Community-Based Firm, Basingstoke, UK: Palgrave Macmillan.

Kodama, M. (2007b), Knowledge Innovation: Strategic Management as Practice, Cheltenham, UK and Northampton, MA, USA: Edward Elgar Publishing.

Kodama, M. (2007c), Project-Based Organization in the Knowledge-Based Society, London, UK: Imperial College Press.

Kodama, M. (2007d), 'Innovation and knowledge creation through leadership-based strategic community: Case study on high-tech company in Japan', Technovation, 27(3), 115-132.

Kodama, M. (2007e), 'Innovation through boundary management: A case study in reforms at Matsushita Electric', Technovation, 27(1-2), 15-29.

Kodama, M. (2009a), 'Boundaries innovation and knowledge integration in the Japanese firm', Long Range Planning, 42(4), 463-494.

Kodama, M. (2009b), Innovation Networks in Knowledge-Based Firm: Developing ICT-Based Integrative Competences, Cheltenham, UK and Northampton, MA, USA: Edward Elgar Publishing.

Kodama, M. (2010a), 'Theoretical framework of dynamic strategic management through boundary management', in Boundary Management, Berlin, Heidelberg: Springer, pp. 15-35.

Kodama, M. (2010b), Developing new business models through dynamic boundary management: Case studies of Sony and NTT-DATA', in Boundary Management, Berlin, Heidelberg: Springer, pp. 37-62.

Kodama, M. (2011), Knowledge Integration Dynamics: Developing Strategic Innovation Capability, Singapore: World Scientific Publishing.

Kodama, M. (2014), Winning Through Boundaries Innovation: Communities of Boundaries Generate Convergence, New York: Peter Lang.

Kodama, M. (2017a), Developing Holistic Leadership: A Source of Business Innovation, Bingley, UK: Emerald Group Publishing.

Kodama, M. (2017b), 'Developing strategic innovation in large corporations: The dynamic capability view of the firm', Knowledge and Process Management, 24(4), 221-246.

Kodama, M. (ed.) (2017c), Ma Theory and the Creative Management of Innovation. Palgrave Macmillan, USA. 
Kodama, M. (2018a), Sustainable Growth Through Strategic Innovation: Driving Congruence in Capabilities, Cheltenham, UK and Northampton, MA, USA: Edward Elgar Publishing.

Kodama, M. (ed.) (2018b), Collaborative Dynamic Capabilities for Service Innovation, London: Palgrave Macmillan.

Kodama, M. (2018c), 'Boundaries innovation through knowledge convergence: Developing triad strategic communities', Technology Analysis \& Strategic Management, 30(5), 609-624.

Kodama, M. (2019), Developing Holistic Strategic Management in the Advanced ICT Era (Vol. 35), Singapore: World Scientific Publishing.

Kodama, M. and Shibata, T. (2014), 'Strategy transformation through strategic innovation capability: A case study of Fanuc', $R \& D$ Management, 44(1), 75-103.

Kodama, M. and Shibata, T. (2016), 'Developing knowledge convergence through a boundaries vision: A case study of Fujifilm in Japan', Knowledge and Process Management, 23(4), 274-292.

Kogut, B. and Zander, U. (1992), 'Knowledge of the firm, combinative capabilities and the replication of technology', Organization Science, 5(2), 383-397.

Leifer, R., McDermott, M., O'Connor, C., Peters, S., Rice, M. and Veryzer, W. (2000), Radical Innovation: How Mature Companies Can Outsmart Upstarts, Cambridge, MA: Harvard Business School Press.

Leonard-Barton, D. (1992), 'Core capabilities and core rigidities: A paradox in managing new product development', Strategic Management Journal, 13(2), 111-125.

Leonard-Barton, D. (1995), Wellsprings of Knowledge: Building and Sustaining the Source of Innovation, Cambridge, MA: Harvard Business School Press.

Levitt, B. and March, J.B. (1988), 'Organization learning', in Scott, W.R. and Blake, J. (eds), Annual Review of Sociology, 14, Palo Alto, CA: Annual Reviews, pp. 319-340.

Lin, L. and Kulatilaka, N. (2006), 'Network effects and technology licensing with fixed fee, royalty, and hybrid contracts', Journal of Management Information Systems, 23(2), 91-118.

March, J.G. (1972), 'Model bias in social action', Review of Educational Research, 42(4), 413-429.

March, J.G. (1981), 'Footnotes to organizational change', Administrative Science Quarterly, 26(4), 563-577.

March, J. (1991), 'Exploration and exploitation in organizational learning', Organization Science, 2(1), $71-87$.

Markides, C. (1999), All the Right Moves: A Guide to Crafting Breakthrough Strategy, Boston, MA: Harvard Business School Publishing.

Martines, L. and Kambil, A. (1999), 'Looking back and thinking ahead: Effects of prior success on managers' interpretations of new information technologies', Academy of Management Journal, 42(3), 652-661.

Miller, C.C. and Ireland, R.D. (2005), 'Intuition in strategic decision making: Friend or foe in the fast-paced 21st century?', The Academy of Management Executive, 19(1), 19-30.

Mintzberg, H. (1978), 'Patterns in strategy formation', Management Science, 24, 934-948.

Mintzberg, H. and Walters, J. (1985), 'Of strategies deliberate and emergent', Strategic Management Journal, 6, 257-272.

Nahapiet, J. and Ghoshal, S. (1998), 'Social capital, intellectual capital, and the creation of value in firms', Academy of Management Review, 23(2), 242-266.

Nonaka, I. and Konno, N. (1998), 'The concept of "ba": Building a foundation for knowledge creation', California Management Review, 40(1), 40-54.

Nonaka, I. and Takeuchi, H. (1995), The Knowledge-Creating Company, New York: Oxford University Press.

Nonaka, I., Kodama, M., Hirose, A. and Kohlbacher, F. (2014), 'Dynamic fractal organizations for promoting knowledge-based transformation: A new paradigm for organizational theory', European Management Journal, 32(1), 137-146.

Owen-Smith, J. and Powell, W.W. (2004), 'Knowledge networks as channels and conduits: The effects of spillovers in the Boston biotechnology community', Organization Science, 15(1), 5-22.

Peirce, C.S. (1998), Chance, love, and logic: Philisophical essays. University of Nebraska Press.

Porter, M.E. and Teisberg, E.O. (2006), Redefining Health Care: Creating Value-Based Competition on Results, Boston, MA: Harvard Business Press. 
Powell, W. and Brantley, P. (1992), 'Competitive cooperation in biotechnology: Learning through networks?' in Noria, N. and Eccles, R.G. (eds), Network and Organizations: Structure, Form and Action, Boston, MA: Harvard Business School, pp. 366-394.

Powell, W., Koput, K. and Smith-Doerr, L. (1996), 'Inter-organizational collaboration and the locus of innovation: Networks of learning in biotechnology', Administrative Science Quarterly, 41, 116-146.

Rafols, I. and Meyer, M. (2010), 'Diversity and network coherence as indicators of interdisciplinarity: Case studies in bionanoscience', Scientometrics, 82(2), 263-287.

Rosenbloom, N. (2000), 'Leadership, capabilities and technological change', Strategic Management Journal, 21, 1083-1103.

Rosenkopf, L. and Nerkar, A. (2001), 'Beyond local search: Boundary-spanning, exploration, and impact in the optical disk industry', Strategic Management Journal, 22(4), 287-306.

Rosenkopf, L. and Tushman, M. (1998), 'The coevolution of community networks and technology: Lessons from the flight simulation industry', Industrial and Corporate Change, 7(6), 311-346.

Ryan, R.M. and Deci, E.L. (2000), 'Self-determination theory and the facilitation of intrinsic motivation, social development, and well-being', American Psychologist, 55(1), 68-78.

Shalley, C.E., Zhou, J. and Oldham, G.R. (2004), 'The effects of personal and contextual characteristics on creativity: Where should we go from here?', Journal of Management, 30(6), 933-958.

Shibata, T., and Kodama, M. (2007), Knowledge integration through networked strategic communities: two case studies in Japan. Business Strategy Series.

Siggelkow, N. (2001), 'Change in the presence of fit: The rise, the fall, and the renaissance of Liz Claiborne', Academy of Management Journal, 44(4), 838-857.

Simon, H.A. (1996), The Science of the Artificial, 3rd edn, Cambridge, MA: MIT Press.

Simon, H.A. (1997), Models of Bounded Rationality: Empirically Grounded Economic Reason (Vol. 3), Cambridge, MA: MIT Press.

Smith, S. and Tushman, M. (2005), 'Managing strategic contradictions: A top management model for managing innovation streams', Organization Science, 16(5), 522-536.

Spender, J.C. (1990), Industry Recipes: An Enquiry into the Nature and Sources of Managerial Judgement, Oxford: Basil Blackwell.

Star, S.L. (1989), 'The structure of ill-structured solutions: Boundary objects and heterogeneous distributed problem solving', in Huhns, M. and Gasser, I.L. (eds), Readings in Distributed Artificial Intelligence, Menlo Park, CA: Morgan Kaufman, pp. 37-54.

Taifi, N. and Passiante, G. (2012), 'Speeding up NPSD through strategic community creation: Case of automaker after-sales services partners', The Service Industries Journal, 32(13), 2115-2127.

Teece, D.J. (2007), 'Explicating dynamic capabilities: The nature and microfoundations of (sustainable) enterprise performance', Strategic Management Journal, 28(13), 1319-1350.

Teece, D.J. (2014), 'The foundations of enterprise performance: Dynamic and ordinary capabilities in an (economic) theory of firms', The Academy of Management Perspectives, 28(4), 328-352.

Teece, D.J., Pisano, G. and Shuen, A. (1997), 'Dynamic capabilities and strategic management', Strategic Management Journal, 18(3), 509-533.

Tripsas, M. and Gavetti, G. (2000), 'Capabilities, cognition, and inertia: Evidence from digital imaging', Strategic Management Journal, 21(10/11), 1147-1161.

Tushman, M.L. (1977), 'Special boundary roles in the innovation process', Administrative Science Quarterly, 22, 587-605.

van Rijnsoever, F.J. and Hessels, L.K. (2011), 'Factors associated with disciplinary and interdisciplinary research collaboration', Research Policy, 40(3), 463-472.

Watts, J. (2003), Six Degrees: The Science of a Connected Age, New York: W.W. Norton and Company.

Zhou, J. and Shalley, C.E. (2007), Handbook of Organizational Creativity, Hove, UK: Psychology Press Limited. 